Review

\title{
Characterization of diarylheptanoids: An emerging class of bioactive natural products
}

\author{
Ágnes Alberti*, Eszter Riethmüller, Szabolcs Béni* \\ Semmelweis University, Department of Pharmacognosy, 1085 Budapest, Üllöi út, 26. Hungary
}

\section{A R T I C L E I N F O}

\section{Article history:}

Received 1 June 2017

Received in revised form 24 August 2017

Accepted 26 August 2017

Available online $\mathrm{xxx}$

\section{Keywords:}

Curcumin

Isolation

LC-MS

NMR

Phytochemical analysis

\begin{abstract}
A B S T R A C T
Diarylheptanoids are a class of secondary plant metabolites with a wide variety of bioactivity. Research on their phytochemistry and phytoanalysis is rapidly growing and the number of identified structures bearing the aryl- $\mathrm{C}_{7}$-aryl skeleton is at present approaching 500 . Historically, the yellow pigment curcumin has been characterized as the first diarylheptanoid and the extensive research on naturally occurring analogues is still ongoing. In this review, studies dealing with the characterization of linear and cyclic derivatives are discussed from the phytoanalytical point of view. Isolation, fractionation and purification strategies from natural sources along with their chromatographic behavior and structural characteristics are discussed. The role of various techniques used for the extraction (such as Soxhlet extraction, sonication, maceration/percolation, microwave-assisted extraction, supercritical carbon dioxide extraction); isolation (liquid-liquid extraction, column chromatographic techniques, preparative thin-layer and high-performance liquid chromatography, centrifugal partition chromatography, counter-current chromatography); separation (thin-layer chromatography, high-performance liquid chromatography, gas chromatography, capillary electrophoresis) and structural characterization (UV/Vis spectroscopy, infrared spectroscopy, X-ray crystallography, mass spectrometry, nuclear magnetic resonance spectroscopy and circular dichroism spectroscopy) are critically reviewed.
\end{abstract}

(C) 2017 Elsevier B.V. All rights reserved.

\section{Contents}

1. Introduction.

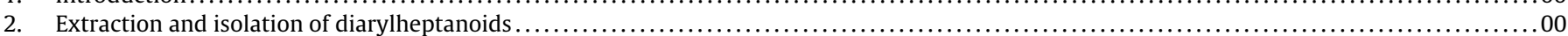

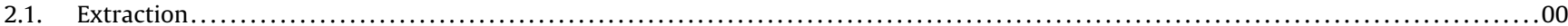

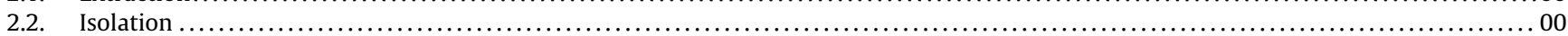

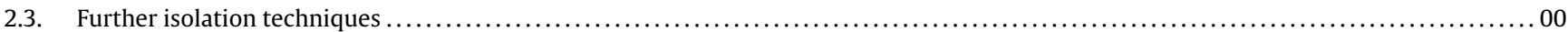

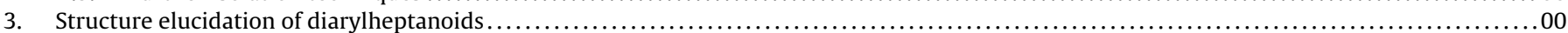

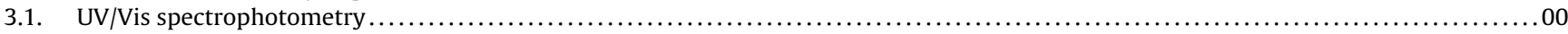

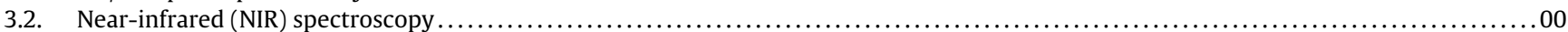

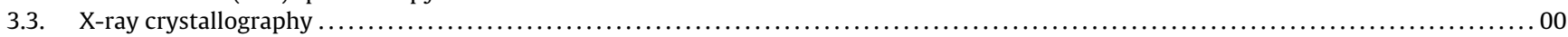

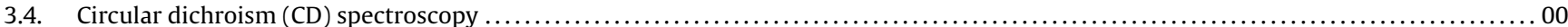

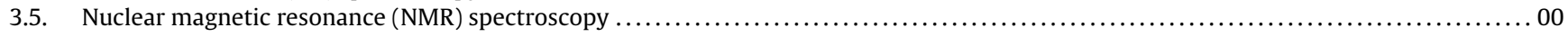

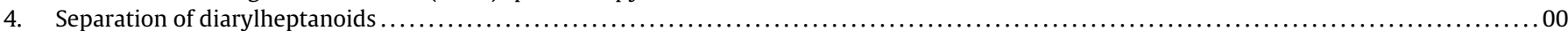

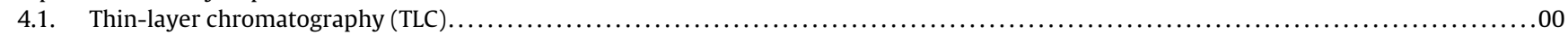

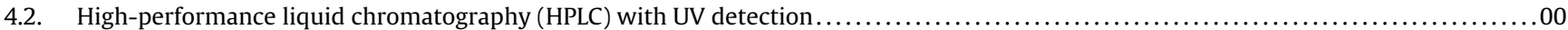

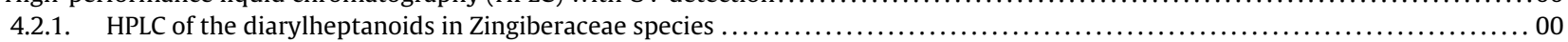

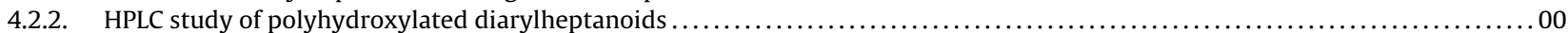

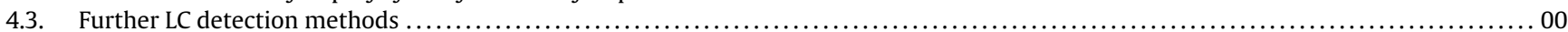

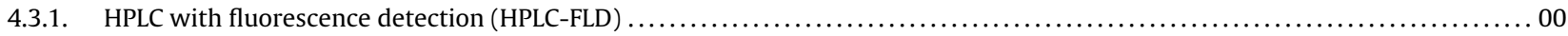

\footnotetext{
* Corresponding authors.

E-mail addresses: alberti.agnes@pharma.semmelweis-univ.hu (Á. Alberti), beni.szabolcs@pharma.semmelweis-univ.hu (S. Béni).
} 


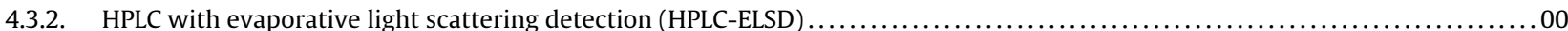

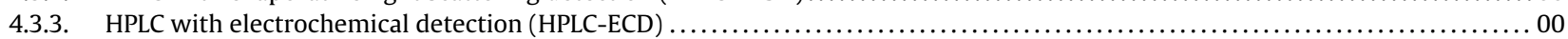

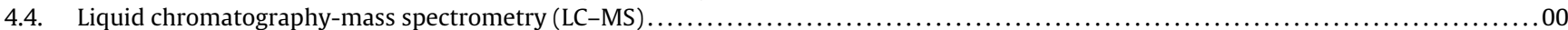

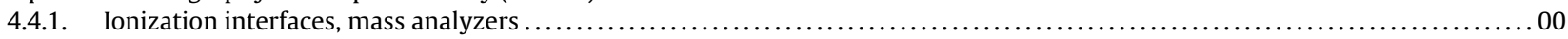

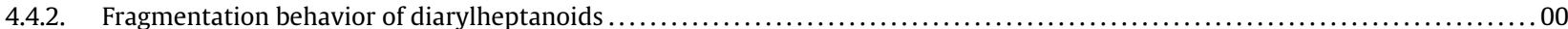

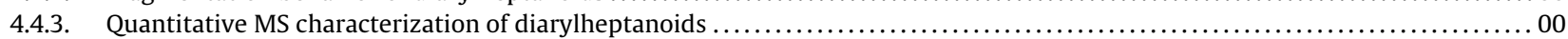

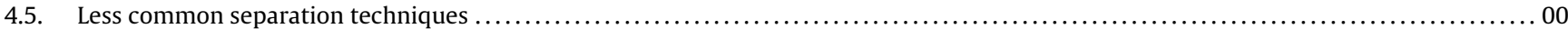

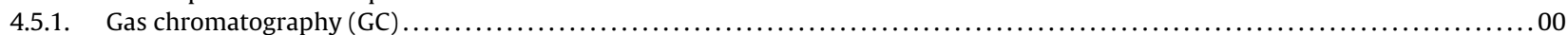

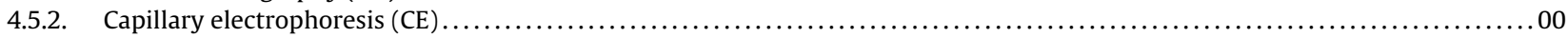

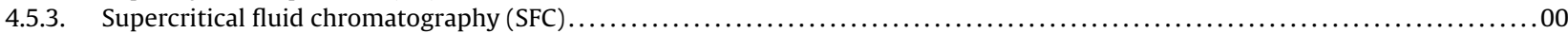

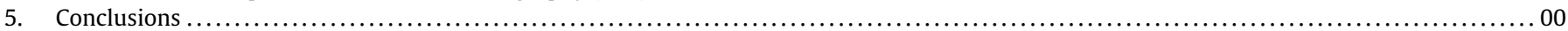

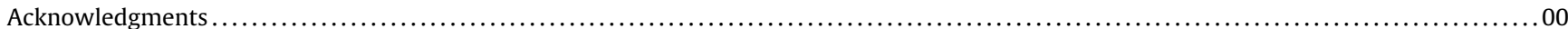

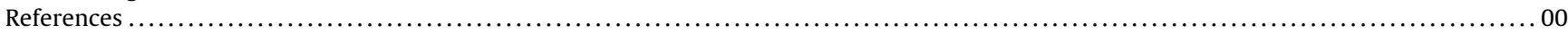

\section{Introduction}

Diarylheptanoids, characterized by a 1,7-diphenylheptane skeleton, constitute a group of natural products gaining emerging interest over the last few decades due to their remarkable biological activities. The more than 400 diarylheptanoids that have been identified so far [1] can be divided into linear or macrocyclic compounds. In diarylether- and biaryl-type constituents the aromatic rings are connected to form [7.1]-meta,para- or [7.0]-meta,metacyclophanes, respectively (Fig. 1) [1-4].

The aromatic rings of linear diarylheptanoids are often hydroxylated or methoxylated. C-4' and C-4" hydroxyl groups can be acetylated or glycosylated, compounds with unsubstituted aromatic rings are scarce. The aliphatic $C_{7}$ chain is either saturated or can have up to three double bonds. Further possibility is the presence of carbonyl groups at C-3 and/or C-5 (Table 1). The C-5 can be substituted by a hydroxyl group that may be free or engaged in another function: methyl, acetyl, sulfate or glycosyl groups can be attached. Diarylheptanoids can occur as mono-, di- or triglycosides. The sugar moieties may be further substituted by phenolcarboxylic acids $[1,2,4,5]$.

According to Lv and She [1,2] (Table 1), linear diarylheptanoids can be divided into several classes. There are compounds, where a 1,5- or a 3,6-oxy bridge (a pyran or a furan ring) is formed within the $C_{7}$ chain (Fig. 2) [6]. Diarylheptanoids can also possess flavonoid (e.g. chalcone, flavanone) moieties at C-5 or C-7 (Fig. 2.) [7]. Dimeric compounds with antiproliferative activity were also isolated from Alpinia species, additionally, a chalcone moiety can also be attached to the dimeric diarylheptanoid skeleton $[8,9]$. The monomeric units can be linked through a pyridine moiety, too (Fig. 2) [10]. Diarylheptanoids bearing a special structure such as 1,3- and 1,5-diarylheptanoids comprise the last class (Table 1) $[2,11]$. Compounds conjugated to an ellagitannin [12] or a gallotannin unit [13] as well as those with a monoterpene [10] or a sesquiterpene moiety [14] have also been reported. Linear diarylheptanoids are abundant in plants of the genera Curcuma, Zingiber, Alpinia (Zingiberaceae), Alnus and Betula (Betulaceae) [1-3].

Cyclic diarylheptanoids are distributed in Myrica (Myricaceae), Acer (Aceraceae), Garuga (Burseraceae), Corylus, Betula, Carpinus (Betulaceae), and Juglans (Juglandaceae) species. The heptane chain of diarylether-type and biaryl-type cyclic diarylheptanoids can be saturated or unsaturated, and carbonyl or hydroxyl groups may also be attached. The aromatic rings can be hydroxylated or methoxylated at certain carbon atoms, $O$-glycosylation can also occur (Figs. 1 and 2) [1-4,15]. A special compound with an ether bond between the side chain and the aryl group has also been isolated (Figs. 1 and 2) [16].

Diarylheptanoids have been reported by numerous studies to possess diverse bioactivities including anti-inflammatory [17], proapoptotic [18], anti-influenza [19], anti-emetic [20], and estrogenic
[21] actions, being their anti-cancer activity that basically has caught the interest of researchers. In vitro and in vivo cytotoxicity against human cancer cell lines of diarylheptanoids has been shown [22,23]. In vivo citotoxicity of oregonin (Fig. 2) has been proved in the B16 murine melanoma model [24]. Although a paper doubting the biological activity and therapeutic utility of curcumin (Fig. 2) due to its unstable, reactive and non-bioavailable properties - has recently been published [25], the interest towards curcuminoids and diarylheptanoids is still undiminished.

\section{Extraction and isolation of diarylheptanoids}

\subsection{Extraction}

There are two prevalent strategies for the extraction of diarylheptanoids. The first method involves the extraction carried out under reflux, in a Soxhlet apparatus, by sonication, or by maceration/percolation with organic solvents such as chloroform, dichloromethane, ethyl acetate, methanol/ethanol, aqueous methanol/ethanol. Although a certain loss may occur, this method allows simple extraction of diarylheptanoids. The initial step is usually followed by subsequent liquid-liquid extractions with hexane, chloroform, ethyl acetate, ethanol, or $n$-butanol [26-31]. The alternative option for diarylheptanoid extraction employs sequential solvent extraction with hexane, chloroform, or ethyl acetate, followed by methanol, ethanol or $n$-butanol [32-34]. A selection of the methods applied in diarylheptanoid extraction and isolation is presented in Table 2.

Extraction techniques aiming to reduce the need for solvents, the extraction time and the costs of producing plant extracts have been developed. In supercritical (and subcritical) fluid extraction (SFE) carbon dioxide is used as the main solvent, thus the consumption of organic solvents can be minimized. With the addition of organic modifiers, higher yields of polar target compounds and a broader range of the extracted constituents can be achieved [48].

Supercritical carbon dioxide extraction [49] and subcritical water extraction [50] have been used to obtain diarylheptanoids from plant materials. Turmeric (Curcuma longa) rhizomes were extracted with supercritical carbon dioxide as well as with supercritical carbon dioxide and ethanol as co-solvent. The addition of ethanol increased the extraction yield of curcuminoids and decreased the solvent consumption. Curcumin is insoluble in water, poorly soluble in hydrocarbon solvents, and soluble in alcohols. Ethanol promoted the solubilization of the polar substances (e.g. diarylheptanoids) present in the rhizomes [51]. Supercritical fluid extraction (SFE) coupled to supercritical fluid chromatography (SFC) has been applied for the analysis of $C$. longa rhizomes. The absence of curcumin in the extracts obtained by pure carbon dioxide was confirmed. The addition of methanol enabled the extraction of the curcuminoids, more than $90 \%$ recovery for curcumin was 

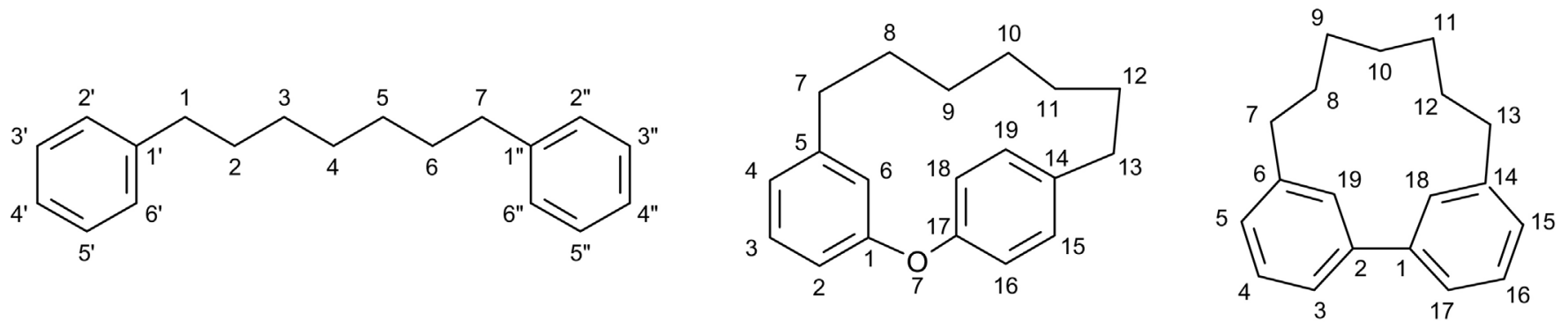

Fig. 1. The chemical structures of linear, diarylether-type and biaryl-type cyclic diarylheptanoids.

Table 1

Structural characteristics of naturally occurring diarylheptanoids according to the classification of Lv and She [2].

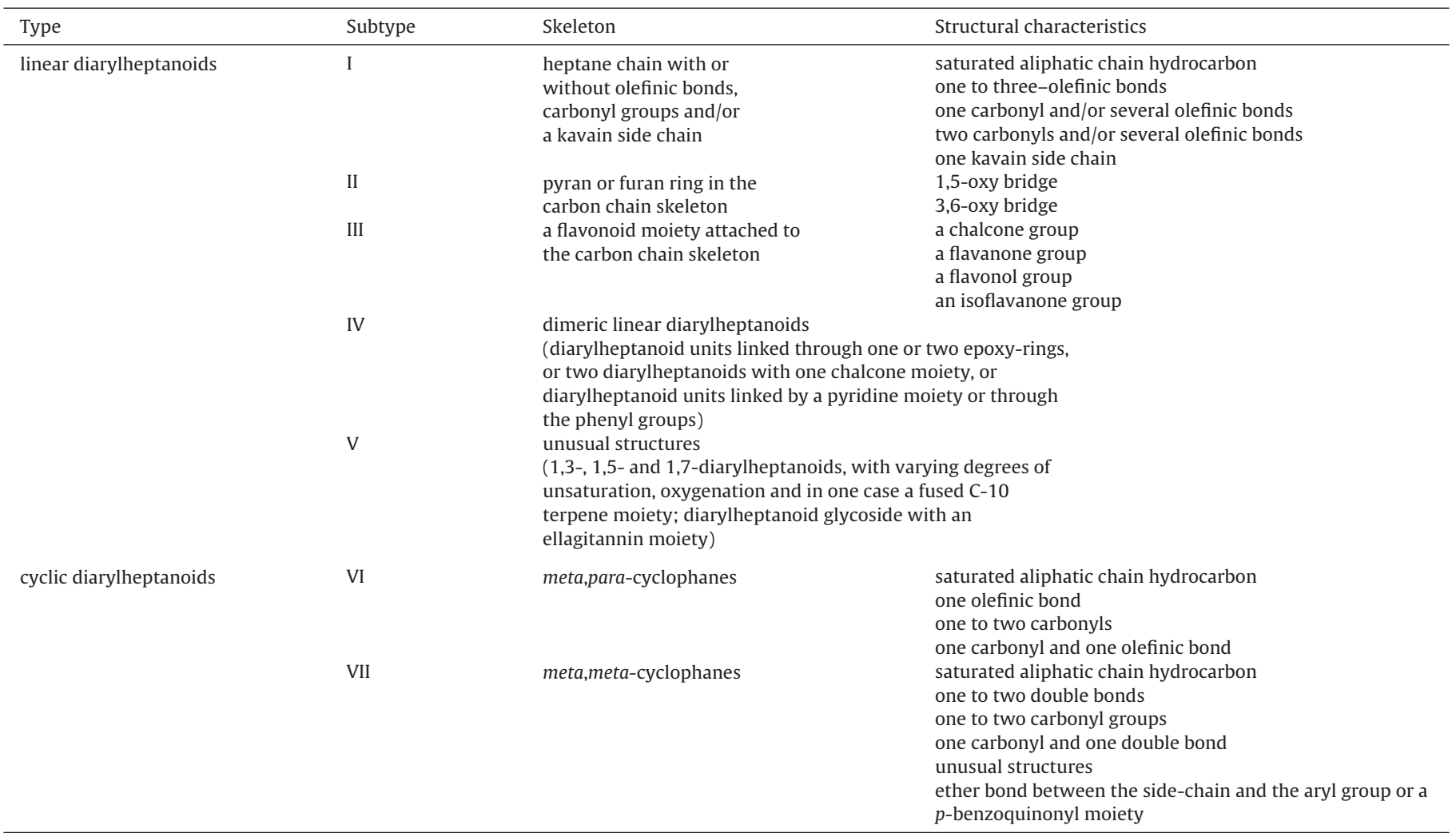

achieved. Higher proportions of methanol, however, would make it impossible to reach the supercritical state, thus causing the loss of the advantages using SFE [52].

A representative thin-layer (TLC) chromatogram of Alnus glutinosa bark SFE extracts obtained with carbon dioxide and different proportions of ethanol can be seen in Fig. 3. The increase in ethanol concentration enhanced the extraction yield, as indicated by the various color intensities of the oregonin and hirsutenone (Fig. 2) zones on the TLC plate.

Further extraction techniques, to obtain diarylheptanoid richextracts, include pressurized liquid extraction (PLE), accelerated solvent extraction (ASE), fluidized bed extraction (FBE), and the use of ionic liquids. Hu et al. developed a pressurized liquid extraction (PLE) method with 70\% aqueous bioethanol as the solvent to obtain diarylheptanoids from Zingiber officinale. In this technique, liquid solvents at elevated temperatures and pressures are used, and as a result, reduced time and solvent volume is required to yield constituents from plants. Additionally, the extracts from PLE showed a different composition compared to Soxhlet extraction, the recovery of diarylheptanoids was significantly improved [53]. Common hazel (Corylus avellana) stems and leaves were extracted by a solid/liquid extraction method, using a solvent system accelerated with static pressurization (Zippertex technology) [54].

Carbamate ionic liquids possess low toxicity and volatility. Additionally, organic compounds show high solubility in carbamate ionic liquids, therefore these liquids have a potential to be used as solvents to overcome low solubility of natural products (e.g. curcumin) in water. Extraction of curcumin from turmeric using a carbamate ionic liquid was investigated, $N, N$-dipropylammonium $N^{\prime}, N^{\prime}$-dipropylcarbamate was used [55]. Extraction of curcuminoids from turmeric was examined using several bromide ionic liquids [56].

Wakte et al. isolated curcumin from the rhizomes of $C$. longa by Soxhlet, microwave-, ultrasound- and supercritical carbon dioxide assisted extraction techniques. The extraction efficiency of the methods was evaluated in terms of curcumin yields and extraction time. High extraction recovery for curcumin in the shortest extraction time was obtained with microwave-assisted extraction [57]. Diverse extraction methods, such as hydrodistillation, low pressure solvent extraction, Soxhlet extraction, and SFE using carbon dioxide with different co-solvents for the extraction of curcuminoids have been compared by Li et al. [58]. Soxhlet extraction, fluidized 
Table 2

Isolation strategies of diarylheptanoids from various plant sources.

\begin{tabular}{|c|c|c|c|c|}
\hline Sample, extraction & Fractionation & Further purification & Isolated diarylheptanoids & Ref. \\
\hline Acer nikoense stem bark & partitioned in EtOAc/ $\mathrm{H}_{2} \mathrm{O}$ & $\begin{array}{l}\text { EtOAc-soluble fraction: silica gel } \\
\text { CC, further separated by silica gel } \\
\text { CC, and prep. HPLC }\end{array}$ & $\begin{array}{l}\text { diarylether-type cyclic compounds: } \\
\text { acerogenins A and I, }(R) \text {-acerogenin B, } \\
\text { 9-oxoacerogenin A, acerosides I, III, VI, } \\
\text { and B1 }\end{array}$ & [35] \\
\hline $\begin{array}{l}\text { hexane; the defatted residue } \\
\text { extracted with } \mathrm{MeOH}\end{array}$ & $\begin{array}{l}\text { the aqueous layer extracted } \\
\text { with } \mathrm{BuOH}\end{array}$ & $\begin{array}{l}\text { BuOH-soluble fraction: Diaion } \\
\text { HP-20 CC, further }\end{array}$ & $\begin{array}{l}\text { biaryl-type cyclic compound: } \\
\text { 9-O-glucosyl-acerogenin } \mathrm{K}\end{array}$ & \\
\hline
\end{tabular}

chromatographed on ODS (and silica gel CC), then prep. HPLC
$\mathrm{CHCl}_{3}-\mathrm{MeOH}(1: 1, \mathrm{v} / \mathrm{v})$, at r.t., with ultrasonic bath in the last hour

Alnus japonica stem bark

$70 \% \mathrm{EtOH}$

Alnus formosana leaves

$\mathrm{MeOH}$

Alnus hirsuta f. sibirica leaves

$80 \% \mathrm{MeOH}$ by ultrasonication at $r . t$.

Alpinia blepharocalyx seeds

95\% EtOH

Alpinia officinarum rhizomes

partitioned with $\mathrm{PE}, \mathrm{CHCl}_{3}$, EtOAc and $n-\mathrm{BuOH}$

$\left(\mathrm{CH}_{2} \mathrm{Cl}_{2}-\mathrm{MeOH}\right.$ gradient,

silica gel VLC

(eluted with $50 \%$ $n$-hexane- $\mathrm{CHCl}_{3}$ and EtOAc, separately) $\mathrm{BuOH}$ $\mathrm{CHCl}_{3}$, EtOAc and $n-\mathrm{BuOH}$

extracted successively with hexane and ether 100:0-60:40, v/v)

liquid-liquid partitioning with

partitioned successively with

$\left(\mathrm{CHCl}_{3}-\mathrm{MeOH}\right.$ gradient

fractions: silica gel CC

( $\mathrm{CHCl}_{3}-\mathrm{MeOH}$ gradient), further subjected to Sephadex LH-20 CC, followed by prep. TLC; epimeric mixtures separated by chiral NP-HPLC

$\mathrm{CHCl}_{3}$ extract: silica gel CC (PE-EtOAc gradient), fractions subjected to silica gel CC (PE-EtOAc)

subfractions: repeated silica gel CC (PE-EtOAc), purified by prep. TLC (PE-Me ${ }_{2} \mathrm{CO}$ or PE-EtOAc) or MPLC (silica gel, $\mathrm{CHCl}_{3}-\mathrm{MeOH}$ or $\mathrm{PE}-\mathrm{Me}_{2} \mathrm{CO}$ ) linear compounds: aceroside VIII,

acerogenin $\mathrm{G},(-)$-centrolobol

linear glycosides: rubranosides A-B

aceroside VII, platyphylloside

platyphyllonol-5-O-xyloside, alnusides A-B, oregonin,

hirsutanonol-5-O-glucoside, 1,7-

diphenylheptan-5-O-glucosyl-3-one,

5-hydroxy-1,7-diphenylheptan-3-0-

xyloside,

1,7-diphenylheptan-5-O-

dimethoxycinnamoylglucosyl-3-one

linear aglycones: hirsutanonol,

hirsutenone

linear diarylheptanoids: hirsutanonol 5-methylhirsutanonol,

platyphyllenone, hirsutenone

cyclic biaryl-type compounds:

myricanone, (+)-S-myricanol,

myricanone 5-O-glucoside,

(+)-S-myricanol-5-O-glucoside,

alnuheptanoid $\mathrm{B}$

linear glycosides: rubranosides A-B

alnusides A-B, aceroside VII, oregonin,

2'"-O-cinnamoyloregonin,

2"'-O-p-coumaroyloregonin,

2 '"-O-benzoyloregonin +4 compds

linear aglycones: hirsutenone

centrolobol, rubranol, hirsutanonol + 5

compds.; methoxy- and butyloxy

derivatives

linear glycosides: aceroside VII,

oregonin,

platyphyllonol-5- 0 -xyloside +5 mono-

and diglycosides

linear aglycones: (+)-hannokinol,

hirsutanonol

5-hydroxy-3-platyphyllone

hirsutenone +3 compds. with

saturated $\mathrm{C}_{7}$ chain and 4 compds. with

unsaturated $C_{7}$ chain

(dimeric) linear compounds with a

chalcone moiety: calyxins A-B, F, H

epicalyxin $B$, 6-hydroxycalyxin $F$

blepharocalyxins A-B

linear compounds with a flavanone

moiety: calyxins C-E, epicalyxins C-D

dimer diarylheptanoid with a pyridine ring: officinaruminane $\mathrm{A}$

diarylheptane monoterpene: officinaruminane $B$

1,7-diphenyl-4-hepten-3-ones: 3 compds.

5-hydroxylated or 5-acetoxylated

linear aglycones: 3 compds.

a diarylheptanoid with a furan ring

diarylheptanoids with a 3,6-furan ring:

alpinoid D + 1 compd. 
Table 2 (Continued)

\begin{tabular}{|c|c|c|}
\hline Sample, extraction & Fractionation & Further purification \\
\hline $\mathrm{MeOH}$ & $\begin{array}{l}\text { the EtOAc-soluble extract was } \\
\text { again partitioned between } \\
n \text {-hexane and } \mathrm{MeOH}-\mathrm{H}_{2} \mathrm{O}\end{array}$ & $\begin{array}{l}\text { MeOH-H } \mathrm{H}_{2} \mathrm{O} \text { extract: Sephadex } \\
\mathrm{LH}-20 \mathrm{CC}(\mathrm{MeOH}) \text {, then Sephadex } \\
\mathrm{LH}-20 \mathrm{CC}\left(\mathrm{CHCl}_{3}-\mathrm{MeOH}\right) \text {, followed } \\
\text { by silica gel CC (n-hexane-EtOAc), } \\
\text { and prep. } \mathrm{HPLC}\left(\mathrm{C} 18, \mathrm{MeOH}-\mathrm{H}_{2} \mathrm{O}\right) \\
\text { or subjected to silica gel CC } \\
\text { (n-hexane-EtOAc gradient), and } \\
\text { prep. HPLC }\left(\mathrm{C} 18, \mathrm{MeOH}-\mathrm{H}_{2} \mathrm{O}\right)\end{array}$ \\
\hline Betula platyphylla inner bark & $\begin{array}{l}\text { residue was extracted with } \\
\mathrm{Et}_{2} \mathrm{O}\end{array}$ & $\begin{array}{l}\mathrm{Et}_{2} \mathrm{O} \text { extract: silica gel CC } \\
\left(\mathrm{CHCl}_{3}-\mathrm{MeOH} \text { and hexane-EtOAc) }\right. \\
\text { and Sephadex LH } 20(\mathrm{MeOH})\end{array}$ \\
\hline $\mathrm{MeOH}$ under reflux & & $\begin{array}{l}\mathrm{Et}_{2} \mathrm{O} \text { insoluble compounds: silica } \\
\text { gel CC }\left(\mathrm{CHCl}_{3}-\mathrm{MeOH}\right) \text { and } \\
\text { Sephadex } \mathrm{LH} 20\left(\mathrm{MeOH}-\mathrm{H}_{2} \mathrm{O}\right) \\
\text { a mixture of aceroside } \mathrm{VII} \text { and } \\
\text { betuloside was purified by droplet } \\
\mathrm{CCC} \text { using } \mathrm{CHCl}_{3}-\mathrm{MeOH}-\mathrm{H}_{2} \mathrm{O} \\
(4: 4: 3, \mathrm{v} / \mathrm{v})\end{array}$ \\
\hline Corylus avellana leaves & $\begin{array}{l}\text { MeOH extract fractionated on } \\
\text { Sephadex } \mathrm{LH}-20 \mathrm{CC}(\mathrm{MeOH})\end{array}$ & $\begin{array}{l}\text { fractions purified by semiprep. } \\
\mathrm{HPLC}\left(\mathrm{C} 18 \text { column, } \mathrm{MeOH}-\mathrm{H}_{2} \mathrm{O}\right)\end{array}$ \\
\hline
\end{tabular}

Curcuma kwangsiensis rhizomes

refluxed with 95\% EtOH, twice

Curcuma kwangsiensis rhizomes

$70 \% \mathrm{EtOH}$

Curcuma longa dried rhizomes

\section{PE and EtOAC}

Hedychium coronarium
rhizomes
$95 \%$ EtOH

Myrica rubra bark
EtOAc extract subjected to silica gel $\mathrm{CC}\left(\mathrm{CH}_{2} \mathrm{Cl}_{2}-\mathrm{MeOH}\right)$

concentrated extract suspended in water and passed through a HP-20 macroporous resin column (EtOH- $\left.\mathrm{H}_{2} \mathrm{O}\right)$

partitioned successively with cyclohexane, EtOAc, and $n-\mathrm{BuOH}$

partitioned in $\mathrm{CHCl}_{3}$ and $n-\mathrm{BuOH}$

extract partitioned with $n$-hexane, EtOAc, and $n-\mathrm{BuOH}$

precipitate separated by $\mathrm{C} 18$ SPE

antitioned in $n$-BuOH- $\mathrm{H}_{2} \mathrm{O}$ silica gel CC (cyclohexane, then $\mathrm{CHCl}_{3}-\mathrm{MeOH}$ gradient)

fractions from silica gel CC: ODS CC $\left(\mathrm{MeOH}-\mathrm{H}_{2} \mathrm{O}\right)$

fractions from ODS CC: Sephadex

$\mathrm{LH}-20 \mathrm{CC}(\mathrm{MeOH})$

fractions from Sephadex $\mathrm{LH}-20 \mathrm{CC}$ : prep. $\mathrm{HPLC}\left(\mathrm{C} 18, \mathrm{MeOH}-\mathrm{H}_{2} \mathrm{O}\right)$ EtOAc extract: silica gel CC, subfractions chromatographed on Sephadex LH-20 CC, then ODS CC or prep. TLC, finally HPLC (C18); enantiomeric mixtures separated by chiral RP-HPLC $\left(\mathrm{ACN}-\mathrm{H}_{2} \mathrm{O}\right)$

repeated $\mathrm{MCI}$ gel $\mathrm{CC}\left(\mathrm{MeOH}-\mathrm{H}_{2} \mathrm{O}\right)$, silica gel CC (PE-EtOAc, then $\mathrm{CH}_{2} \mathrm{Cl}_{2}-\mathrm{MeOH}$ ), and Sephadex $\mathrm{LH}-20 \mathrm{CC}\left(\mathrm{MeOH}-\mathrm{H}_{2} \mathrm{O}\right)$

BuOH fraction: Sephadex LH-20 CC $(\mathrm{MeOH})$

fractions: $\mathrm{CPC}\left(\mathrm{CHCl}_{3}-\mathrm{MeOH}-\mathrm{H}_{2} \mathrm{O}\right.$ or $\mathrm{CHCl}_{3}-\mathrm{MeOH}-\mathrm{H}_{2} \mathrm{O}-n-\mathrm{PrOH}$; normal followed by reverse mode) subfractions: silica gel CC. Sephadex LH-20 CC, semiprep. C18 HPLC

EtOAc extract: Toyopearl HW-40C $\mathrm{CC}\left(\mathrm{MeOH}-\mathrm{H}_{2} \mathrm{O}\right.$ and $\left.\mathrm{H}_{2} \mathrm{O}-\mathrm{Me}_{2} \mathrm{CO}\right)$, then YMC-gel ODS CC

$\left(\mathrm{MeOH}-\mathrm{H}_{2} \mathrm{O}\right)$, finally Sephadex LH-20 CC (EtOH)

n-BuOH extract: Toyopearl $\mathrm{HW}-40 \mathrm{C} \mathrm{CC}\left(\mathrm{MeOH}-\mathrm{H}_{2} \mathrm{O}\right.$ and $\mathrm{H}_{2} \mathrm{O}-\mathrm{Me}_{2} \mathrm{CO}$ ), then $\mathrm{C} 18 \mathrm{CC}$ $\left(\mathrm{MeOH}-\mathrm{H}_{2} \mathrm{O}\right)$

elute from C18 SPE: prep. NP-TLC

$n$-BuOH soluble fraction subjected to normal and reversed-phase silica gel CC, and prep. HPLC
Isolated diarylheptanoids

linear compounds with unsaturated $C_{7}$

chain alpinoid $\mathrm{E}+5$ compd.

hydroxylated or methoxylated linear compounds with saturated $C_{7}$ chain: 10 compds.

linear glycosides: acerosides VII-VIII

1,7-diphenyl-3-hepten-5-one and a 2-hydroxy derivative

cyclic diarylheptanoids: acerogenin $\mathrm{E}$ 3,5'-dihydroxy-4'-methoxy-3',4"-oxo1,7-diphenyl-1-heptene

diarylether-type cyclic diarylheptanoids:

with 1 or 2 unsaturated bonds in the $C_{7}$ chain: giffonins $\mathrm{A}-\mathrm{H}$

biaryl-type cyclic diarylheptanoid

diglycoside: giffonin I

diarylheptanoids with a

tetrahydropyran ring (1,5-epoxy

derivatives): 3 compds.

3,5-dihydroxy-1,7-diphenylheptanes: 4 compds.

3-acetoxy-5-hydroxy-1,7-

diphenylheptanes: 4

compds.

3,5-diacetoxy-1,7-diphenylheptanes: 3 compds.

3-hydroxylated or 3-acetoxylated linear aglycones with saturated and unsaturated $C_{7}$ chain: 12 compds.

linear aglycones with saturated and unsaturated $C_{7}$ chain: 6 compds. diarylheptanoids with a sesquiterpene moiety: bisabolocurcumin ether derivatives

1,5-diphenylpenta-1,4-dien-3-one 1,7-diphenylhepta-1,4,6-trien-3-one diarylheptanoids with a tetrahydropyran ring: hedycoropyrans $\mathrm{A}-\mathrm{C}$ with a tetrahydrofuran ring: hedycorofurans A-D

biaryl-type cyclic diarylheptanoids

myricanol, myricanone, actinidione, myricanone

5-O-(6'-O-galloyl)-glucoside, $(R)$ - and (S)-myricanol

5-O-(6'-O-galloyl)-glucosides myricanol 11-sulfate, juglanin B 11-sulfate

biaryl-type cyclic diarylheptanoids: myricanane A-B

5-O-arabinosyl-glucosides; myricanone and its 5-O-glucoside, neomyricanone-5-O-glucoside, myricanol and its 11-O-glucoside, (+)-S-myricanol-5-O-glucoside 

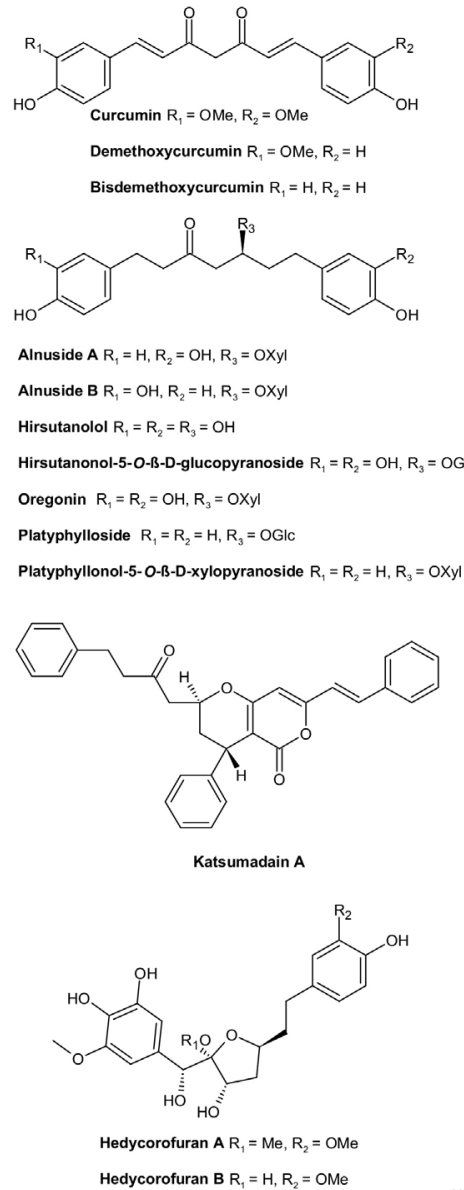

Hedycorofuran $B \mathrm{R}_{1}=\mathrm{H}, \mathrm{R}_{2}=\mathrm{OMe}$

Hedycorofuran $C \mathrm{R}_{1}=\mathrm{Me}, \mathrm{R}_{2}=H$

Hedycorofuran $D R_{1}=R_{2}=H$

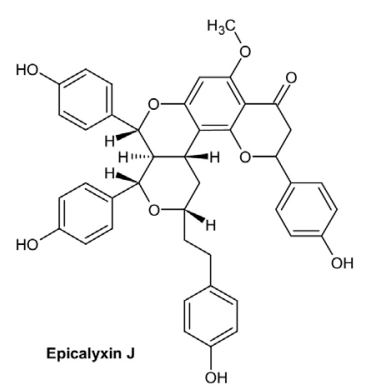

Epicalyxin $\mathrm{J}$<smiles>COc1cc(CCC(=O)CC(=O)CCc2ccc(O)c(OC)c2)ccc1O</smiles>

Tetrahydrocurcumin<smiles>[R6]c1cc(CCC([R8])C[C@@H]([R8])CCc2ccc(O)c(Br)c2)ccc1O</smiles>

3,5-diacetoxy-7-(3,4-dihydroxyphenyl)-1-(4-hydroxy3-methoxyphenyl)heptane $R_{1}=O H R_{2}=O M e, R_{3}=O A c, R_{4}=O A C$ Aceroside VII $R_{1}=R_{2}=H, R_{3}=O G I c, R_{4}=H$

(-)-Centrolobol $R_{1}=H=H, R_{3}=O H, R_{4}=H$

Rubranoside $A R_{1}=R_{2}=O H, R_{3}=O G \mid c, R_{4}=H$

Rubranoside $B R_{1}=R_{2}=O H, R_{3}=O X y l, R_{4}=H$

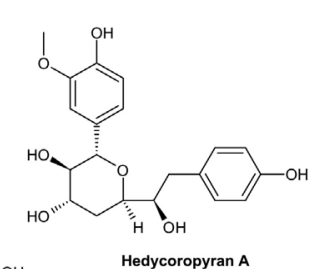<smiles>[R6]c1cc(CCC(=O)/C=C/CCc2ccc(O)c(Br)c2)ccc1O</smiles>

Platyphyllenone $R_{1}=R_{2}=H$

Alusenone $\mathrm{R}_{1}=\mathrm{H}, \mathrm{R}_{2}=\mathrm{OH}$

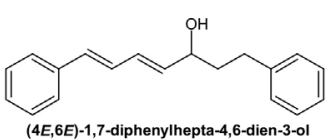

(4E,6E)-1,7-diphenylhepta-4,6-dien-3-ol

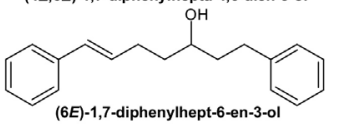

(6E)-1,7-diphenylhept-6-en-3-01<smiles>O=C(CC/C=C/c1ccccc1)CCc1ccccc1</smiles>

(6E)-1,7-diphenylhept-6-en-3-one<smiles>[R]c1cc(CC(O)[C@H]2C[C@H](O)[C@@H](O)[C@H](c3ccc(O)c(OC)c3)O2)ccc1O</smiles>

Hedycoropyran B R $=\mathrm{H}, 3 \otimes$

Hedycoropyran $\mathrm{C} \mathrm{R}=\mathrm{OH}, 3 \mathrm{~W}$

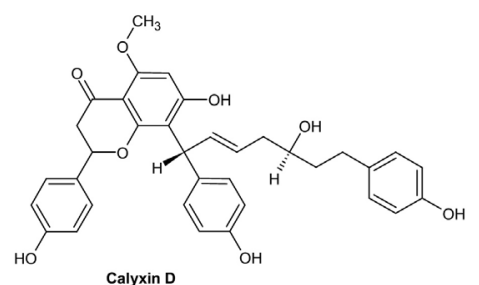

Calyxin D
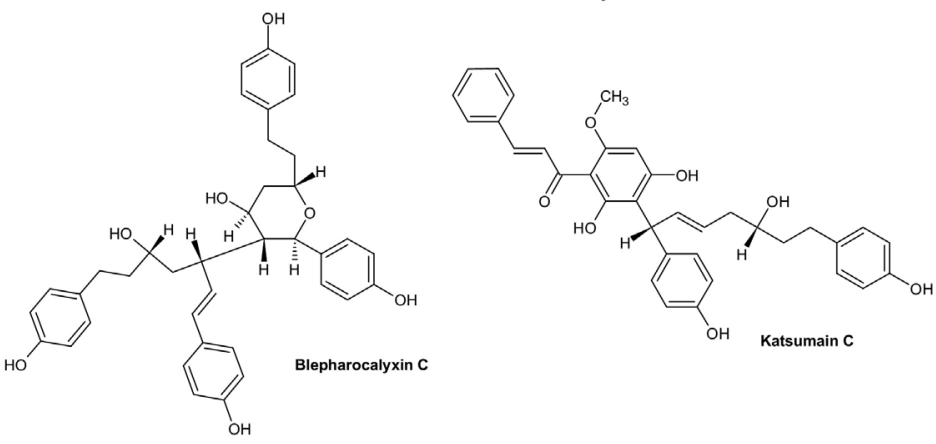

Katsumain C

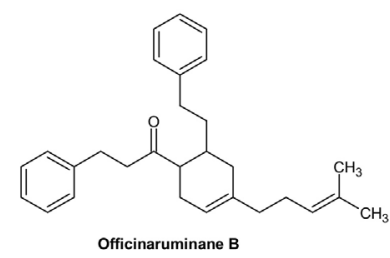

Officinaruminane $\mathrm{A}$

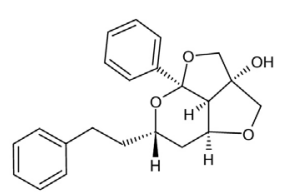

Diocollettines A

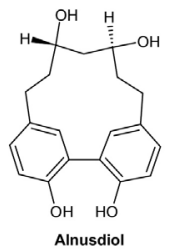

Fig. 2. Structures of selected diarylheptanoids discussed in the review. 
Table 2 (Continued)

\begin{tabular}{|c|c|c|c|c|}
\hline Sample, extraction & Fractionation & Further purification & Isolated diarylheptanoids & Ref. \\
\hline \multicolumn{5}{|l|}{$\mathrm{MeOH}$} \\
\hline $\begin{array}{l}\text { Pyrostria major leaves } \\
\text { EtOAc }\end{array}$ & $\begin{array}{l}\text { subjected to silica gel CC } \\
\left(\mathrm{CH}_{2} \mathrm{Cl}_{2}-\mathrm{MeOH} \text { gradient }\right)\end{array}$ & $\begin{array}{l}\text { fractions were purified by prep. } \\
\mathrm{HPLC}(\mathrm{C} 18 \text { column; MeOH-0.1\% } \\
\mathrm{HCOOH} \text { in } \mathrm{H}_{2} \mathrm{O} \text { gradient) }\end{array}$ & $\begin{array}{l}\text { 3-OD-glucosides of 5-formyl-3- } \\
\text { hydroxy-1,7-diphenylheptanes and } \\
\text { 3,5-dihydroxy-1,7-diphenylhepanes }\end{array}$ & [46] \\
\hline $\begin{array}{l}\text { Renealmia alpinia rhizomes, } \\
\text { Renealmia cernua leaves }\end{array}$ & $\begin{array}{l}\text { partitioned between } \\
\mathrm{H}_{2} \mathrm{O}-\mathrm{CHCl}_{3} \text { and } \mathrm{H}_{2} \mathrm{O} \text {-EtOAc }\end{array}$ & $\begin{array}{l}\mathrm{CHCl}_{3} \text { phase: silica gel } \mathrm{CC} \\
\text { (PE-EtOAC gradient, then } \\
\text { EtOAc-MeOH), then silica gel MPLC } \\
\text { (PE-EtOAc or } \mathrm{CHCl}_{3}-\mathrm{MeOH} \\
\text { gradient) }\end{array}$ & $\begin{array}{l}\text { linear aglycones with saturated and } \\
\text { unsaturated } C_{7} \text { chain: renecernin, } \\
\text { hirsutanonol, renealpin, hirsutenone, } \\
\text { platyphyllenone, alusenone, } \\
\text { tetrahydrobisdemethoxycurcumin }\end{array}$ & [47] \\
\hline $\mathrm{MeOH}$ at r.t. & & $\begin{array}{l}\text { EtOAc phase: Sephadex LH-20 CC } \\
(\mathrm{MeOH}), \text { then silica gel MPLC } \\
\left(\mathrm{CHCl}_{3}-\mathrm{MeOH}\right) \text {, and cyclic MPLC }\end{array}$ & & \\
\hline Zingiber officinale rhizomes & $\begin{array}{l}\text { alcoholic residue was } \\
\text { partitioned with PE, EtOAc, and } \\
n-\mathrm{BuOH}\end{array}$ & $\begin{array}{l}\text { EtOAc extract: silica gel CC } \\
\text { (PE-EtOAc gradient), repeated } \\
\text { silica gel CC and Sephadex LH-20 } \\
\mathrm{CC}\left(\mathrm{CHCl}_{3}-\mathrm{MeOH} \text { or }\right. \\
\text { benzene-Me } \mathrm{MeO}_{2} \mathrm{Cr} \text { grients), then } \\
\text { prep. TLC }\end{array}$ & $\begin{array}{l}\text { linear methoxylated aglycones with } \\
\text { saturated and unsaturated } C_{7} \text { chain: } \\
\text { hexahydrocurcumin, gingerenones } A \text {, } \\
C+5 \text { compds. }\end{array}$ & [30] \\
\hline \multirow[t]{2}{*}{ soaked in $95 \%$ EtOH at r.t. } & & $\begin{array}{l}\text { n-BuOH extract: silica gel CC } \\
\text { ( } \mathrm{CHCl}_{3}-\mathrm{MeOH} \text { gradient), repeated } \\
\text { silica gel } \mathrm{CC}\left(\mathrm{CHCl}_{3}-\mathrm{MeOH}-\mathrm{H}_{2} \mathrm{O} \text { or }\right. \\
\left.\mathrm{CHCl}_{3}-\mathrm{MeOH}-\mathrm{AcOH}_{\text {gradients }}\right) \text {, or } \\
\text { Sephadex } \mathrm{LH}-20 \mathrm{CC}(\mathrm{MeOH})\end{array}$ & a linear diacetoxylated aglycone & \\
\hline & & & $\begin{array}{l}\text { 1,5-epoxy-diarylheptanoids: } 4 \text { compds. } \\
\text { sulfated diarylheptanoids: } \\
\text { shogasulfonic acid A+2 compds. }\end{array}$ & \\
\hline
\end{tabular}

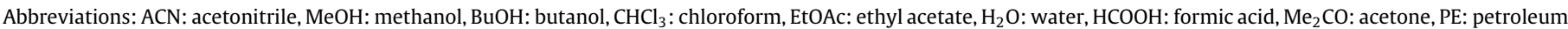

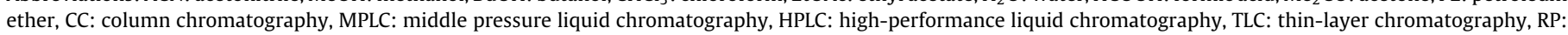
reversed-phase, NP: normal-phase, r.t.: room temperature.

bed extraction, and accelerated solvent extraction methods were applied using organic solvents of different polarity (hexane, ethyl acetate, and ethanol) to obtain diarylheptanoid-rich extracts from Alnus incana and A. glutinosa, the Soxhlet method possessed the highest extraction efficiency for diarylheptanoids [59].

\subsection{Isolation}

The extracted diarylheptanoids can be fractionated using open column chromatography (CC), vacuum liquid chromatography (VLC) $[34,60,61]$, middle pressure liquid chromatography (MPLC) $[62,63]$, flash chromatography $[64,65]$, preparative thin-layer chromatography (TLC) [66], or preparative high-performance liquid chromatography (HPLC) (Table 2) [67]. Cyclic MPLC has also been employed [47]. The most common procedures apply normal-phase chromatography on silica gel, gel filtration on Sephadex LH-20, and reversed-phase chromatography using C18-bonded silica columns or Diaion HP-20 resin [8,68-71]. Solvents including various mixtures of hexane, chloroform, ethyl acetate, and methanol are used. 2,3-Digalloyl oregonin was isolated from the $80 \%$ acetone extract of Alnus sibirica leaves by column chromatography using Amberlite XAD-2, Sephadex LH-20, MCI-gel, CHP 20P and ODS-B gel with an MPLC system [13]. Diarylheptanoid sulfates were isolated by the combination of size exclusion and reversed-phase chromatography $[44,72]$ or by a sequential application of both together with normalphase chromatography [73]. The $\mathrm{AgNO}_{3}$ column chromatography of the petroleum ether extract of Alpinia officinarum yielded the highly lipophilic diarylheptanoid 1,7-diphenylhept-3-ene-5-one [74]. Commercially available curcumin consists of a mixture of the three main curcuminoids, where curcumin is the major compound, while demethoxycurcumin and bisdemethoxycurcumin (Fig. 2.) are present only as minor constituents. In a recent study, a purification process to obtain the three curcuminoids as pure compounds has been reported. Repeated crystallizations followed by silica gel CC of the remaining mother liquors yielded the pure compounds with high recoveries. However, the authors claimed that puri- fied curcumin rapidly degraded, while demethoxycurcumin and bisdemethoxycurcumin were found to be more stable, and their presence in the mixture enhanced the stability of curcumin [75].

The isolation of the compounds frequently requires several subsequent or repeated applications of chromatographic techniques [76]. However, it is also possible to obtain the compounds just in a few fractionation steps. Masullo et al. isolated hydroxylated diarylether-type and biaryl-type macrocyclic diarylheptanoids (giffonins J-P, Fig. 2) from the methanol extract of $C$. avellana leaves. The extract was fractionated on a Sephadex LH-20 column, and the fractions were further purified by semipreparative HPLC on a C18 column [77]. Novaković et al. extracted the bark of A. glutinosa with a chloroform-methanol $(1: 1, \mathrm{v} / \mathrm{v})$ mixture and fractionated the crude extract on a silica gel column with different gradient elution systems. Similar fractions from the silica gel CC were combined after TLC analysis and further fractionated by semi-preparative HPLC on a C18 column into pure compounds [78]. During the isolation of diarylheptanoid glycosides with cinnamoyl moieties attached to the glucose residues, acid-catalyzed and photochemical cis-trans isomerization of the double bond in the cinnamic acids occurred $[79,80]$. Purification of these compounds by HPLC using pure water instead of $0.025 \%$ formic acid as the aqueous eluent yielded pure constituents [36].

Diarylheptanoids possessing a diarylheptanoid and a chalcone moiety were isolated from Alpinia blephyarocalyx and Alpinia katsumadai as epimeric mixtures, e.g. calyxins B-C, F, H, and katsumain $\mathrm{C}$, together with their epimers epicalyxins $\mathrm{B}-\mathrm{C}, \mathrm{F}$, $\mathrm{H}$, and 7-epikatsumain $\mathrm{C}$, respectively (Fig. 2). These stereoisomers could be separated by preparative HPLC on a chiral column [81-83]. Dong et al. isolated an enantiomeric mixture of diarylheptanoids with a tetrahydropyran skeleton from Dioscorea villosa. (1S,3S,5S)- and (1R,3R,5R)-1,7-bis(4-hydroxyphenyl)-1,5-epoxy-3hydroxyheptanes were again separated by normal-phase HPLC on a chiral column [84]. 


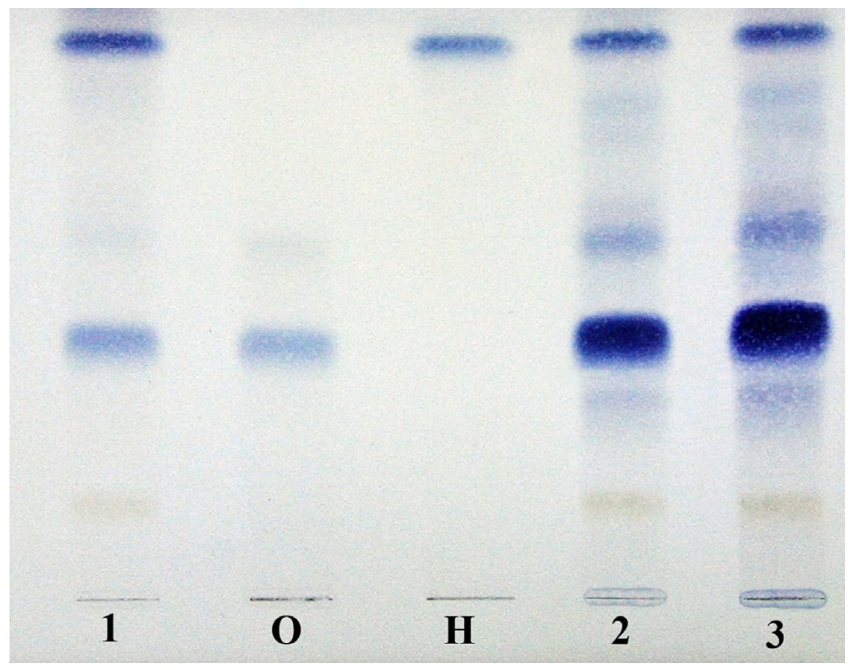

Fig. 3. TLC chromatogram of A. glutinosa SFE extracts. 1: A. glutinosa $10 \%$ EtOH SFE extract, O: oregonin standard solution, H: hirsutenone standard solution, 2: A. glutinosa 15\% EtOH SFE extract, 3: A. glutinosa 20\% EtOH SFE extract. Stationary phase: silica gel $60 \mathrm{~F}_{254} 10 \times 10 \mathrm{~cm}$, mobile phase: chloroform:methanol:formic acid $(75: 25: 2, v / v)$, post-chromatographic derivatization: vanillin-sulfuric acid reagent $\left(0.5 \mathrm{~g}\right.$ vanillin in $100 \mathrm{ml}$ sulfuric acid-ethanol, $40: 10, \mathrm{v} / \mathrm{v}$ ), heating at $100-105^{\circ} \mathrm{C}$. SFE extracts: dried and milled black alder bark samples $(0.6 \mathrm{~g})$ were extracted for one hour, at $40{ }^{\circ} \mathrm{C}$ and $20 \mathrm{MPa}$ with $10 \%, 15 \%$, and $20 \%$ ethanol, in a Jasco system $\left(\mathrm{CO}_{2}\right.$ pump with a cooling system, pump, mixer, extraction vessels, column thermostat, back-pressure regulator).

\subsection{Further isolation techniques}

Diarylheptanoids with estrogenic activity from the seeds of Amomum longiligulare were separated by high-speed countercurrent chromatography (HSCCC) and purified by HPLC [85].

$\mathrm{Wu}$ et al. obtained six diarylheptanoids from the petroleum ether fraction of $A$. officinarum rhizome methanol extract by counter-current chromatography (CCC) using a three-phase solvent system consisting of $n$-hexane, ethyl acetate, acetonitrile, and water, while preparative C18 HPLC was used for further purification [86]. The diarylheptanoid 1,7-diphenyl-4,6-heptadien-3-one, together with five flavonoids was isolated from A. katsumadai by microwave-assisted extraction (MAE) followed by HSCCC. The two-phase solvent system was composed of hexane-ethyl acetate-methanol-water [87].

The methanol extract of Betula platyphylla inner bark was subjected to silica gel CC (eluted with chloroform-methanol and hexane-ethyl acetate mixtures) and Sephadex LH-20 CC to obtain a mixture of the arylbutanoid glucoside betuloside and the linear diarylheptanoid glucoside aceroside VII (Fig. 2). The mixture was subjected to droplet CCC to obtain the pure compounds [40]. HSCCC was used for preparative scale separation of the active constituents from the ethanol extract of Alnus japonica stems. HSCCC separation of the ethyl acetate fraction from the crude extract yielded hirsutanonol-5-O- $\beta$-D-glucopyranoside, 3-deoxohirsutanonol-5-O- $\beta$-D-glucopyranoside, and hirsutenone with recoveries of $95.4 \%, 97.0 \%$, and $93.7 \%$ (purities: $94.7 \%, 90.5 \%$, and $98.6 \%$, respectively [88].

Oregonin was isolated from the methanol extract of Alnus formosana leaves that was subjected to liquid-liquid partitioning. The $n$-butanol soluble fraction was separated on a Sephadex LH-20 column to provide an oregonin-rich fraction that was further purified by CPC to yield pure oregonin [89]. Abedini et al. also aimed to optimize the isolation of oregonin from the methanol extract of $A$. glutinosa bark. Fractionation of the crude extract was performed by $\mathrm{CPC}$ using a three-phase solvent system resulting in a recovery of
$72 \%$ (850 mg) for oregonin at purity higher than $94 \%$ after a single injection [90].

Hedycoropyrans A-C containing a tetrahydropyran moiety and hedycorofurans A-D (Fig. 2) comprising a tetrahydrofuran moiety were isolated from the ethanol extract of Hedychium coronarium rhizomes. The $n$-butanol soluble fraction was separated on a Sephadex LH-20 column, the fractions were subjected to CPC using two-phase solvent systems. Further separation of the CPC subfractions using silica gel and Sephadex LH-20 CC and semi-preparative HPLC (C18) yielded pure compounds [6].

\section{Structure elucidation of diarylheptanoids}

\subsection{UV/Vis spectrophotometry}

All diarylheptanoids exhibit absorption in the range of 250-290 nm. Curcumin presents a further broad absorption band in the visible region with a maximum in the $410-430 \mathrm{~nm}$ range. Curcumin exhibits keto-enol tautomerism, where the enol form is characterized by the formation of a strong intramolecular hydrogen bond. Additionally, curcumin is ready to form intermolecular $\mathrm{H}$-bonds in solution. Thus, the intense absorption band in the visible region appears due to the extended conjugated system of the aromatic rings, the unsaturated bonds in the $C_{7}$-chain, and the intramolecular H-bonding of the enol function [91-94]. The UV/Vis absorption spectrum of curcumin in acetonitrile can be seen in Fig. 4.

UV/Vis spectrophotometry is commonly used for the quantification of total curcuminoid content of medicinal plant extracts, formulations, food, etc. [95,96]. The European Pharmacopoeia 9th edition publishes two official herbal drug monographs, Turmeric rhizome and Javanese turmeric (Curcumae longae rhizoma and Curcumae zantorrhizae rhizoma), which require the quantitative determination of total dicinnamoyl methane derivatives (expressed as curcumin) using a spectrophotometric method for the quality control of the drugs. Absorption of ethanol extracts prepared by a reflux method is measured at $425 \mathrm{~nm}[97,98]$. These spectrophotometric methods are, however, not suitable to quantify the individual curcuminoids.

Ahmed et al. elucidated the encapsulation of curcumin preparing different lipid-based nanoemulsions and conventional emulsions. Additionally, the bioaccessibility of curcumin was investigated, when released in an in vitro model simulating small intestine digestion conditions. The concentration of curcumin in lipid phases was determined by spectrophotometry [99].

\subsection{Near-infrared (NIR) spectroscopy}

Tanaka et al. developed a quantitation method for the determination of curcumin, demethoxycurcumin, and bisdemethoxycurcumin in turmeric samples, using NIR spectroscopy and multivariate statistics. Characteristic absorptions of curcuminoids around $1620-1740 \mathrm{~nm}$ could be assigned to $\mathrm{C}-\mathrm{H}$ stretching vibrations, while substitution of the benzene ring - reducing the symmetry of the molecule - generated additional vibrational bands in the region of $2100-2550 \mathrm{~nm}$. The prediction of the composition in the pulverized turmeric samples by partial least-squares regression (PLS-R) analysis showed high correlation with the results from HPLC quantitation [100]. Kasemsumram et al. reported an application of moving window partial least squares regression (MWPLSR) to determine the total curcuminoid content in rhizomes of $C$. longa by NIR spectroscopy [101]. 


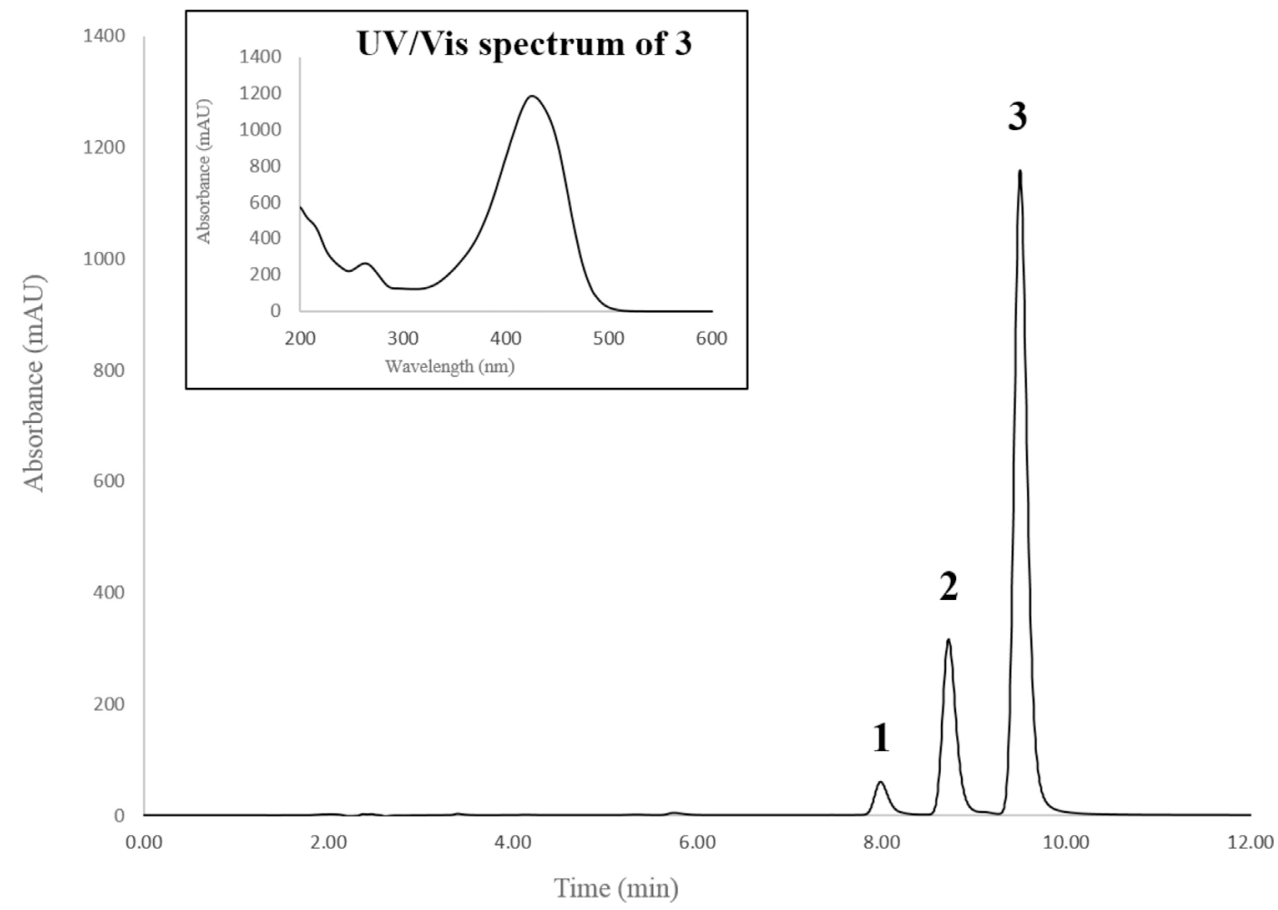

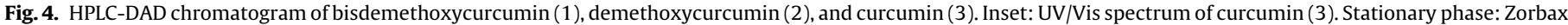

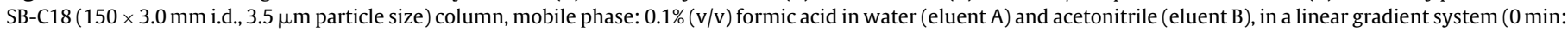

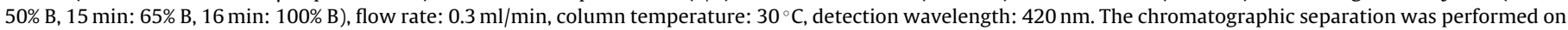
an Agilent 1100 HPLC system (degasser, binary gradient pump, autosampler, column thermostat, diode array detector).

\subsection{X-ray crystallography}

X-ray crystallographic analysis of diarylheptanoids is commonly applied to investigate the absolute structure of the compounds. The structure of the plane-chiral compound, $(R)-(+)$-galeon from Myrica gale var. tomentosa was determined by direct X-ray crystallographic analysis of the corresponding $p$-bromobenzoate derivative [102]. The absolute configuration of the biaryl-type diarylheptanoid (-)-alnusdiol (Fig. 2) and the relative configuration of the diarylether-type compound (-)-maximowicziol A, isolated from the heartwood of Betula maximowicziana, were proposed according to X-ray and CD analyses [76]. The absolute configuration of diocollettines A (Fig. 2), a diarylheptanoid derivative from Dioscorea collettii with an unusual skeleton where 6/5/5 fused rings are attached to the heptane chain, was also assigned, according to single-crystal X-ray diffraction and experimental electronic circular dichroism (ECD) data. Triclinic crystals of diocollettines A, formed after crystallization in cyclohexane/dichloromethane, were studied by X-ray crystallography [103]. Powder X-ray diffraction was used for the characterization of purified curcumin, demethoxycurcumin, and bisdemethoxycurcumin solid phases [75].

\subsection{Circular dichroism (CD) spectroscopy}

Curcumin is an achiral molecule [91], however, several diarylheptanoids bear a stereogenic center on the $C_{7}$ moiety (e.g. giffonins A-I), while giffonins J-P are characterized by at least two stereogenic centers in the alkyl chain [104]. There are also derivatives lacking an asymmetric carbon atom but possessing planar or axial chirality, e.g. $(R)-(+)$-galeon [102,105]. Tedarene B isolated from the marine sponge Tedania ignis shows central, axial, and planar chirality in the same molecule [106].

The stereochemistry of hedycoropyrans A-C and hedycorofurans $A-D$, isolated from $H$. coronarium rhizomes was evaluated by ECD spectroscopic analyses [6]. The sulfonated linear diarylhep- tanoid C-1 epimers, kaempsulfonic acids A and B were obtained from the rhizomes of Kaempferia galanga. ECD spectroscopic data were compared with those from the computational calculation method. Additionally, molybdenum(II) acetate induced circular dichroism (ICD) was also applied for the establishment of their absolute configurations [72]. The relative configurations of the biaryl-type giffonins $\mathrm{T}$ and $\mathrm{U}$ from $C$. avellana could be assigned by a combined quantum mechanical/NMR approach, the orientations of the hydroxyl groups on the heptyl chain, however, could not be determined. The absolute configurations were finally assigned, according to comparison of calculated and experimental ECD spectra [104]. The absolute configurations of some diarylheptanoids could be determined based on the data from the CD exciton chirality analyses of the corresponding 3,5-bis-p-bromobenzoyl and 3,5-bis-p-dimethylaminobenzoyl derivatives [46,107].

\subsection{Nuclear magnetic resonance (NMR) spectroscopy}

The NMR characteristics of naturally occurring linear and cyclic diarylheptanoids characterized until 2012 have been reviewed by Lv and She [1,2]. They provided a comprehensive collection of 409 distinct structures along with the available ${ }^{13} \mathrm{C}$ NMR data of the aglycones. Due to the plethora of core structures, a wide selection of NMR solvents was applied for sample preparation. Irrespective of the core type (linear or cyclic) altogether $2 \cdot 6=12$ (diaryl) +7 (heptanoid) $=19$ carbon atoms build up the diarylheptane skeleton . The structure identification, however, starts with the evaluation of the ${ }^{1} \mathrm{H}$ NMR spectrum which provides several entry points into the structure identification. Careful inspections of the aromatic region furnish the number and pattern of substitutions on the aromatic rings (usually $\mathrm{ABX}$ or $\mathrm{AA}^{\prime} \mathrm{XX}$ ' systems) and also provide the number of unsaturation ( $\mathrm{sp}^{2}$ carbon-bound hydrogens) in the heptane chain (if any). Counting the aliphatic resonances in the heptane chain also suggests the type of substitution such as hydroxylation or the presence of keto group(s) as well. The number of methoxy 
substitution can also be evident from the ${ }^{1} \mathrm{H}$ NMR spectrum, similarly to the presence of any glycosylation. The ${ }^{1} \mathrm{H}^{1}{ }^{1} \mathrm{H}$ connectivities and the individual resonances of each spin system are usually mapped by COSY and TOCSY experiments, while these separated spin systems are attached to each other using the direct ${ }^{1} \mathrm{H}_{-}{ }^{13} \mathrm{C}$ and long-range ${ }^{1} \mathrm{H}_{-}{ }^{13} \mathrm{C}$ spin-spin couplings. Some representative examples presenting straightforward structure elucidation of linear diarylheptanoids can be found in references [32,43,46,108,109], while those of the cyclic derivatives are reported in $[34,76,104,110]$.

The relative stereochemistry of linear diarylheptanoids (especially of those bearing other moieties) [111] and that of the cyclic ones [77] are usually established through NOESY/ROESY data. Masullo et al. have also deduced the relative configurations of giffonins by comparing experimental and predicted ${ }^{1} \mathrm{H}$ and ${ }^{13} \mathrm{C}$ values [77]. Further structural confirmations (site of glycosylation, absolute configuration of chiral centers) require chemical transformation of the compounds and subsequent NMR data collection on the modified structure. The removal of the sugar moieties is usually completed by acid hydrolysis, while unknown stereochemistry is resolved by the derivatization of diarylheptanoids by Mosher's acid.

The bioactivity-guided approaches are emerging in the field of natural product discovery [112], in which NMR can also facilitate the identification of the bioactive compounds by pattern recognition strategy. Abedini et al. [90] reported the use of ${ }^{13} \mathrm{C}$ NMR dereplication method for the unambiguous identification of oregonin, hirsutanonol, and alusenon 1a in the methanol extract of A. glutinosa bark. ${ }^{1} \mathrm{H}$ NMR-guided fractionation was also successfully applied for the identification of new linear diarylheptanoid structures produced by $D$. villosa. The ${ }^{1} \mathrm{H}$ iterative Full Spin Analysis (HiFSA) highlighted the characteristic doublets (AA'XX' system) of the para-disubstituted aromatic rings allowing the identification of several pyran-containing diarylheptanoid isomers [84].

Further advantage of NMR spectroscopy resides in its application as a detector in hyphenated techniques. With the use of HPLC-SPE-NMR, a pre-screening of the plant extract is possible thereby facilitating the identification of minor and new compounds in complex plant matrices. Yi-Chun et al. successfully applied this setup for the identification of ten diarylheptanoids in the $n$-butanol fraction of $A$. formosana leaves [17].

As NMR can also provide dynamic data on flexible molecules as well, solution conformation of curcumin was also determined by the NMR analysis of molecular flexibility in solution (NAMFIS) method. ${ }^{1} \mathrm{H}-{ }^{1} \mathrm{H}$ distances derived from quantitative NOE measurements and ${ }^{3} \mathrm{~J}$ coupling-derived dihedral angle constraints helped to identify individual contributing conformers to the solution distribution of curcumin [113].

\section{Separation of diarylheptanoids}

\subsection{Thin-layer chromatography (TLC)}

Tønnesen et al. analyzed the applicability of different TLC systems for the estimation of curcuminoid content in turmeric samples. Separation of the three curcuminoids could be achieved using normal-phase silica gel TLC plates and a mobile phase with a mixture of chloroform-ethanol. Tailing of the spots, irreversible adsorption of the samples, and degradation of the colored compounds was observed. Chromatographic separation of curcumin, demethoxycurcumin, and bisdemethoxycurcumin on silica gel TLC plates can be unsatisfactory, because of the intense tailing, which occurs due to the enolic and phenolic moieties in the compounds. Addition of acid to the mobile phase reduced the tailing without impairing the separation. To overcome the difficulties regarding TLC separation and quantitation of curcuminoids, alternative methods applying modified stationary phases were also developed. With an amino-bonded stationary phase curcumin showed improved stability and decreased adsorption to the stationary phase at the application spot [114], while Rasmussen et al. reported the separation of curcuminoids using dihydrogen phosphate impregnated silica gel TLC plates [115].

The monographs of the European Pharmacopoeia require the identification of the official herbal drugs Curcumae longae rhizoma and Curcumae zanthorrhizae rhizoma by the detection of curcuminoids using TLC. The extracts of the drugs are separated on silica gel F254 plates with a mobile phase of acetic acid-toluene (20:80, $\mathrm{v} / \mathrm{v})$. Curcuminoids are detected without derivatization at $365 \mathrm{~nm}$ as green fluorescent zones. After post-chromatographic derivatization with anisaldehyde solution and heating at $100-105^{\circ} \mathrm{C}$, they can be visualized as reddish, brown and yellow zones at $365 \mathrm{~nm}$ $[97,98]$.

A high-performance thin-layer chromatographic (HPLTC) method - providing reduced analysis time and more compact zones as compared to TLC - was developed for the simultaneous quantitation of curcuminoids in C. longa and Curcuma amada samples. The separation was achieved on silica gel $60 \mathrm{~F}_{254}$ HPLTC plates eluted with a mobile phase of chloroform-methanol. UV detection at $366 \mathrm{~nm}$ was applied, since it afforded better resolution compared to that at $430 \mathrm{~nm}$ [116]. Pathania et al. improved a quantitative HPTLC method using a stationary phase with spherical silica particles providing better resolution, reproducibility, and dense bands, as compared to other plates [117]. Another HPTLC method with densitometric detection at $430 \mathrm{~nm}$ was developed and validated for the analysis of curcumin as a bulk drug and in formulations. In this method, 10 min saturation of the chamber with the mobile phase could also improve resolution and resulted in a sharp zone for curcumin. The limits of detection and quantitation were $8 \mathrm{ng} / \mathrm{spot}$ and $25 \mathrm{ng} / \mathrm{spot}$, respectively [118]. Similar results were reported by Paramasivam et al. for the densitometric analysis of the three curcuminoids. The limit of quantitation was estimated to be $0.1 \mu \mathrm{g} / \mathrm{spot}$, the linearity of the method was analyzed in the range of 1-20 $\mu \mathrm{g} / \mathrm{spot}$ for the three compounds [119].

A validated HPTLC method was developed for the quality control of Alnus nepalensis and the quantification of the linear diarylheptanoid aglycones platyphyllenone, alusenone, hirsutenone, and hirsutanonol, as marker compounds (Fig. 2). The quantitation was carried out by densitometry at $610 \mathrm{~nm}$ after derivatization with vanillin-sulfuric acid reagent [120]. As a follow up to this work, the diarylheptanoid glycosides platyphylloside, oregonin, and hirsutanonol-5-O- $\beta$-D-glucopyranoside (Fig. 2) were quantified in A. nepalensis by a validated HPTLC method. The linearity of the method was proved in the range of 333-3330 ng/spot [121].

As a representative example, the TLC separation of diarylheptanoids from A. glutinosa SFE extracts is shown in Fig. 3. The linear diarylheptanoid glycosides and aglycones appeared in visible light as blue zones, the presence of oregonin and hirsutenone was proved by comparison of their retention factors with those of standard compounds.

\subsection{High-performance liquid chromatography (HPLC) with UV detection}

High-performance liquid chromatography and recently ultrahigh-pressure liquid chromatography (UHPLC) are the most relevant separation methods in diarylheptanoid analysis. Chromatographic separation is usually performed in the reversedphase mode, on C18-bonded silica columns. Both isocratic and gradient elution systems are applied, with water containing acetate or formate buffer, and methanol or acetonitrile as the most common eluents. The addition of acid to the aqueous eluent can prevent the formation of diarylheptanoid phenolate (or enolate) ions, therefore the resolution of diarylheptanoids can be improved 
Table 3

HPLC methods for the analysis of diarylheptanoids in different sample matrices.

\begin{tabular}{|c|c|c|c|c|c|}
\hline Detected compounds & Sample & $\begin{array}{l}\text { Stationary phase } \\
\text { temperature }\end{array}$ & Mobile phase $(\mathrm{v} / \mathrm{v})$, flow rate & Detection & Ref. \\
\hline $\begin{array}{l}\text { C, DMC, BDMC } \\
\text { validated (ICH) }\end{array}$ & Curcuma longa & $\begin{array}{l}\text { Waters BEH Shield RP C18 } \\
2.1 \times 100 \mathrm{~mm}, 1.7 \mu \mathrm{m} \\
30^{\circ} \mathrm{C}\end{array}$ & $\begin{array}{l}0.05 \% \text { phosphoric acid in } \mathrm{H}_{2} \mathrm{O}-\mathrm{ACN} \\
34: 66 \\
0.4 \mathrm{ml} / \mathrm{min}\end{array}$ & $420 \mathrm{~nm}$ & [124] \\
\hline C, DMC, BDMC & $\begin{array}{l}\text { standard solutions, } \\
\text { turmeric } \mathrm{MeOH} \text { extracts }\end{array}$ & $\begin{array}{l}\text { Discovery } 1 \mathrm{HS} \mathrm{C} 18,3 \mu \mathrm{m}, \\
150 \times 2.1 \mathrm{~mm} \\
40^{\circ} \mathrm{C}\end{array}$ & $\begin{array}{l}\text { A: } 5 \mathrm{mM} \mathrm{HCOONH}_{4} \text { and } 0.1 \% \mathrm{HCOOH} \text { in } \\
\mathrm{H}_{2} \mathrm{O}, \mathrm{B}: \mathrm{ACN} \\
0 \mathrm{~min}: 5 \% \mathrm{~B}, 2 \mathrm{~min}: 5 \% \mathrm{~B}, 57 \mathrm{~min}: 100 \% \\
\text { B, } 60 \mathrm{~min}: 100 \% \mathrm{~B}, 65 \mathrm{~min}: 5 \% \mathrm{~B} \text {, } \\
75 \mathrm{~min}: 5 \% \mathrm{~B} ; 0.25 \mathrm{ml} / \mathrm{min}\end{array}$ & $\begin{array}{l}\text { FTICR QIT MS } \\
(-) \text { and (+)-ESI MS }\end{array}$ & [125] \\
\hline C, DMC, BDMC quantification & SFE extracts of Curcuma & $\begin{array}{l}\text { Shimadzu Hypersil } \\
\text { ODS-C18 } 250 \times 4.5 \mathrm{~mm} \\
\text { ambient temperature }\end{array}$ & $\begin{array}{l}\mathrm{CH}_{3} \mathrm{COOH} \text { with the } \mathrm{pH} \text { adjusted to } \\
2.88 \text {, prepared in the proportion of } \\
55: 45 \text { with } \mathrm{ACN} \text { and } \mathrm{H}_{2} \mathrm{O} \\
1 \mathrm{ml} / \mathrm{min}\end{array}$ & $425 \mathrm{~nm}$ & [51] \\
\hline $\begin{array}{l}\text { curcumin } \\
\text { quantification }\end{array}$ & C. longa ethanol extract & $\begin{array}{l}\text { Lichrosphere RP C18 } \\
250 \times 4 \mathrm{~mm}\end{array}$ & $\begin{array}{l}\mathrm{MeOH}-\mathrm{IPA}-\mathrm{H}_{2} \mathrm{O}-\mathrm{CH}_{3} \mathrm{COOH} \\
20: 27: 48: 5 \\
0.5 \mathrm{ml} / \mathrm{min}\end{array}$ & $420 \mathrm{~nm}$ & {$[96]$} \\
\hline $\begin{array}{l}\text { curcumin } \\
\text { quantification validated } \\
\text { (AOAC International) }\end{array}$ & $\begin{array}{l}\text { food, dietary supplements } \\
\text { containing } C \text {. longa }\end{array}$ & $\begin{array}{l}\text { Kinetex C18 } \\
2.1 \times 30 \mathrm{~mm}, 2.6 \mu \mathrm{m} \\
55^{\circ} \mathrm{C}\end{array}$ & $\begin{array}{l}\text { A: } 0.1 \% \mathrm{HCOOH} \text { in } \mathrm{H}_{2} \mathrm{O}, \mathrm{B}: 0.1 \% \mathrm{HCOOH} \\
\text { in } \mathrm{ACN} \\
0 \mathrm{~min}: 28 \% \mathrm{~B}, 1 \mathrm{~min}: 28 \% \mathrm{~B}, 2 \mathrm{~min}: 30 \% \\
\text { B, } 4 \mathrm{~min}: 30 \% \mathrm{~B}, 4.1 \mathrm{~min}: 50 \% \mathrm{~B} \text {, } \\
6.0 \mathrm{~min}: 50 \% \mathrm{~B} ; 1.4 \mathrm{ml} / \mathrm{min}\end{array}$ & $425 \mathrm{~nm}$ & {$[126]$} \\
\hline $\begin{array}{l}\text { C, DMC, BDMC quantitation } \\
\text { validated }\end{array}$ & $\begin{array}{l}\text { food samples (tablets, } \\
\text { candies, tea) }\end{array}$ & $\begin{array}{l}\text { Senshu Pak PEGASIL ODS } \\
\mathrm{C} 18,2 \times 150 \mathrm{~mm}, 5 \mu \mathrm{m}\end{array}$ & $\begin{array}{l}\text { A: } 0.01 \% \mathrm{CH}_{3} \mathrm{COOH} \text { in } \mathrm{H}_{2} \mathrm{O} \text {, B: } \mathrm{ACN} \\
0 \text { min: } 45 \% \text { B, } 15 \mathrm{~min}: 95 \% \mathrm{~B} ; 0.2 \mathrm{ml} / \mathrm{min}\end{array}$ & $\begin{array}{l}\text { ESI-MS/MS } \\
\text { SIM }\end{array}$ & [127] \\
\hline curcumin degradation kinetics & standard solutions & $\begin{array}{l}\text { Waters C18 } \\
150 \times 3.9 \mathrm{~mm}, 5 \mu \mathrm{m} \text { and } \\
\text { J.T. Baker C18 } \\
150 \times 3.9 \mathrm{~mm}, 5 \mu \mathrm{m}\end{array}$ & $\begin{array}{l}\mathrm{MeOH}-1 \% \mathrm{CH}_{3} \mathrm{COOH} \text { in } \mathrm{H}_{2} \mathrm{O} 35: 65 \text { and } \\
\text { THF- } \mathrm{H}_{2} \mathrm{O} 40: 60,1 \% \text { citric acid, } \mathrm{pH} 3.0 \\
1.0 \mathrm{ml} / \mathrm{min}\end{array}$ & $280 \mathrm{~nm}$ & {$[128]$} \\
\hline $\begin{array}{l}\text { C, THC } \\
\text { quantitation, validated }\end{array}$ & rat plasma & $\begin{array}{l}\text { Phenomenex Luna } \\
\text { C18 } 250 \times 4.6 \mathrm{~mm}\end{array}$ & $\begin{array}{l}\mathrm{ACN}-\mathrm{H}_{2} \mathrm{O} 70: 30 \text {, with } 0.005 \% \\
\mathrm{CH}_{3} \mathrm{COOH} \\
0.2 \mathrm{ml} / \mathrm{min}\end{array}$ & $\begin{array}{l}(-)-E S I \text { MS/MS } \\
\text { MRM }\end{array}$ & [129] \\
\hline $\begin{array}{l}\text { curcumin, glucuronide and } \\
\text { sulfate conjugates } \\
\text { quantification }\end{array}$ & human plasma & $\begin{array}{l}\mu \text { Bondapak C18 } \\
250 \times 4.6 \mathrm{~mm}, 10 \mu \mathrm{m}\end{array}$ & $\begin{array}{l}\text { A: } 0.1 \% \mathrm{CH}_{3} \mathrm{COOH}-65 \% \mathrm{MeOH}-35 \% \\
\mathrm{H}_{2} \mathrm{O}, \mathrm{B}: \mathrm{MeOH} \\
0 \mathrm{~min}: 100 \% \text { of } \mathrm{A}, 15 \mathrm{~min}: 0 \% \mathrm{~A} ; 2.0 \\
\mathrm{ml} / \mathrm{min}\end{array}$ & $420 \mathrm{~nm}$ & {$[130]$} \\
\hline $\begin{array}{l}\text { DPH-4,6-dien-3ol } \\
\text { DPH-6-en-3-ol }\end{array}$ & $\begin{array}{l}\text { nanoemulsions of Curcuma } \\
\text { comosa hexane extract }\end{array}$ & $\begin{array}{l}\text { Thermo Hypersil silica } \\
250 \times 4.6 \mathrm{~mm}, 5 \mu \mathrm{m} \\
25^{\circ} \mathrm{C}\end{array}$ & $\begin{array}{l}n \text {-hexane- } \mathrm{CH}_{2} \mathrm{Cl}_{2} 35: 65 \\
1.5 \mathrm{ml} / \mathrm{min}\end{array}$ & 302 or $250 \mathrm{~nm}$ & [131] \\
\hline $\begin{array}{l}\text { DPH-6-en-3-one } \\
\text { DPH-6-en-3-ol } \\
\text { DPH-4,6-dien-3-ol } \\
\text { quantitation validated }\end{array}$ & $\begin{array}{l}\text { plasma, brain, liver, kidney, } \\
\text { ovary, uterus samples }\end{array}$ & $\begin{array}{l}250 \times 4 \mathrm{~mm}, 5 \mu \mathrm{m} \\
25 \pm 1^{\circ} \mathrm{C}\end{array}$ & n-hexane- $\mathrm{CH}_{2} \mathrm{Cl}_{2}$ 40:60 & 302 or $250 \mathrm{~nm}$ & {$[132]$} \\
\hline THC, galanganol C & $\begin{array}{l}\text { Zingiber mioga and Zingiber } \\
\text { officinale } \mathrm{MeOH} \text { extract }\end{array}$ & $\begin{array}{l}\text { Acquity BEH C18 } \\
100 \times 2.1 \mathrm{~mm}, 1.7 \mu \mathrm{m}\end{array}$ & $\begin{array}{l}\mathrm{ACN}-\mathrm{H}_{2} \mathrm{O} \text { containing } 0.1 \% \mathrm{HCOOH} \\
0 \mathrm{~min}: 5 \% \mathrm{~A}, 10 \mathrm{~min}: 100 \% \text { A, } 12 \mathrm{~min}: \\
5 \% \mathrm{~A} \\
0.3 \mathrm{ml} / \mathrm{min}\end{array}$ & $(-)$ and $(+)$ QTOF MS & [133] \\
\hline acetoxy diarylheptanoids & $\begin{array}{l}\text { Z. officinale rhizome, root, } \\
\text { leaf, shoot }\end{array}$ & $\begin{array}{l}\text { Discovery HS C18 } \\
150 \times 2.1 \mathrm{~mm}, 3 \mu \mathrm{m}\end{array}$ & $\begin{array}{l}\text { A: } 5 \mathrm{mM} \mathrm{HCOONH} 4 \text { and } 0.1 \% \mathrm{HCOOH} \text { in } \\
\mathrm{H}_{2} \mathrm{O}, \mathrm{B}: \mathrm{ACN} \\
0 \mathrm{~min}: 5 \% \mathrm{~B}, 2 \mathrm{~min}: 5 \% \mathrm{~B}, 57 \mathrm{~min}: 100 \% \\
\text { B, } 60 \mathrm{~min}: 100 \% \text { B, } 65 \mathrm{~min}: 100 \% \mathrm{~B} \text {; } \\
0.25 \mathrm{ml} / \mathrm{min}\end{array}$ & $\begin{array}{l}(-) \text { and }(+) \text {-ESI MS } \\
\text { IT MS/MS }\end{array}$ & {$[134,135]$} \\
\hline $\begin{array}{l}10 \text { diarylheptanoids } \\
\text { quantitation (DAD) }\end{array}$ & $\begin{array}{l}\text { steamed } Z \text {. officinale } \\
\text { rhizome }\end{array}$ & $\begin{array}{l}\text { Zorbax Extend-C18 } \\
4.6 \times 150 \mathrm{~mm}, 5 \mu \mathrm{m} \\
25^{\circ} \mathrm{C}\end{array}$ & $\begin{array}{l}\text { A: } \mathrm{H}_{2} \mathrm{O}, \mathrm{B}: \mathrm{ACN} \\
0 \mathrm{~min}: 20 \% \mathrm{~B}, \mathrm{~min}: 90 \% \mathrm{~B}, \mathrm{~min}: 100 \% \mathrm{~B} \text {, } \\
100 \% \mathrm{~B} \\
1 \mathrm{ml} / \mathrm{min}\end{array}$ & $\begin{array}{l}280 \mathrm{~nm} \\
(+)-\mathrm{TOF} \mathrm{MS}\end{array}$ & {$[136]$} \\
\hline 7 diarylheptanoids & $\begin{array}{l}\text { MeOH extracts of } \\
\text { Renealmia alpinia } \\
\text { Renealmia cernua }\end{array}$ & $250 \times 4.6 \mathrm{~mm}, 5 \mu \mathrm{m}$ & $\begin{array}{l}\text { A: } 15 \mathrm{mM} \text { ortho-phosphoric acid and } \\
1.5 \mathrm{mM} \text { tetrabutylammonium } \\
\text { hydroxide in } \mathrm{H}_{2} \mathrm{O} \text {, B: } \mathrm{MeOH} \\
0 \text { min: } 20 \% \mathrm{~B}, 17 \mathrm{~min}: 90 \% \mathrm{~B}, 20 \mathrm{~min} \text { : } \\
100 \% \text { B, } 28 \mathrm{~min}: 100 \% \mathrm{~B} ; 1.0 \mathrm{ml} / \mathrm{min}\end{array}$ & $230 \mathrm{~nm}$ & [47] \\
\hline $\begin{array}{l}\text { hexahydrocurcumin, } \\
\text { yakuchinone A } \\
\text { quantification }\end{array}$ & $\begin{array}{l}\text { Alpinia officinarum leaves } \\
\mathrm{MeOH} \text { extract }\end{array}$ & $2.1 \times 50 \mathrm{~mm}, 2.6 \mu \mathrm{m}$ & $\begin{array}{l}0 \mathrm{~min}: 0 \% \mathrm{~B}, 0.01 \mathrm{~min}: 2 \% \mathrm{~B}, 1.01 \mathrm{~min}: \\
2 \% \mathrm{~B}, 1.02 \mathrm{~min}: 35 \% \mathrm{~B}, 4.02 \mathrm{~min}: 35 \% \mathrm{~B} \text {, } \\
15.02 \mathrm{~min}: 90 \% \mathrm{~B}, 15.03 \mathrm{~min}: 2 \% \mathrm{~B} \\
20.02 \mathrm{~min}: 2 \% \mathrm{~B} ; 0.3 \mathrm{ml} / \mathrm{min}\end{array}$ & $(+)-E S I M S / M S$ & [137] \\
\hline
\end{tabular}


Table 3 (Continued)

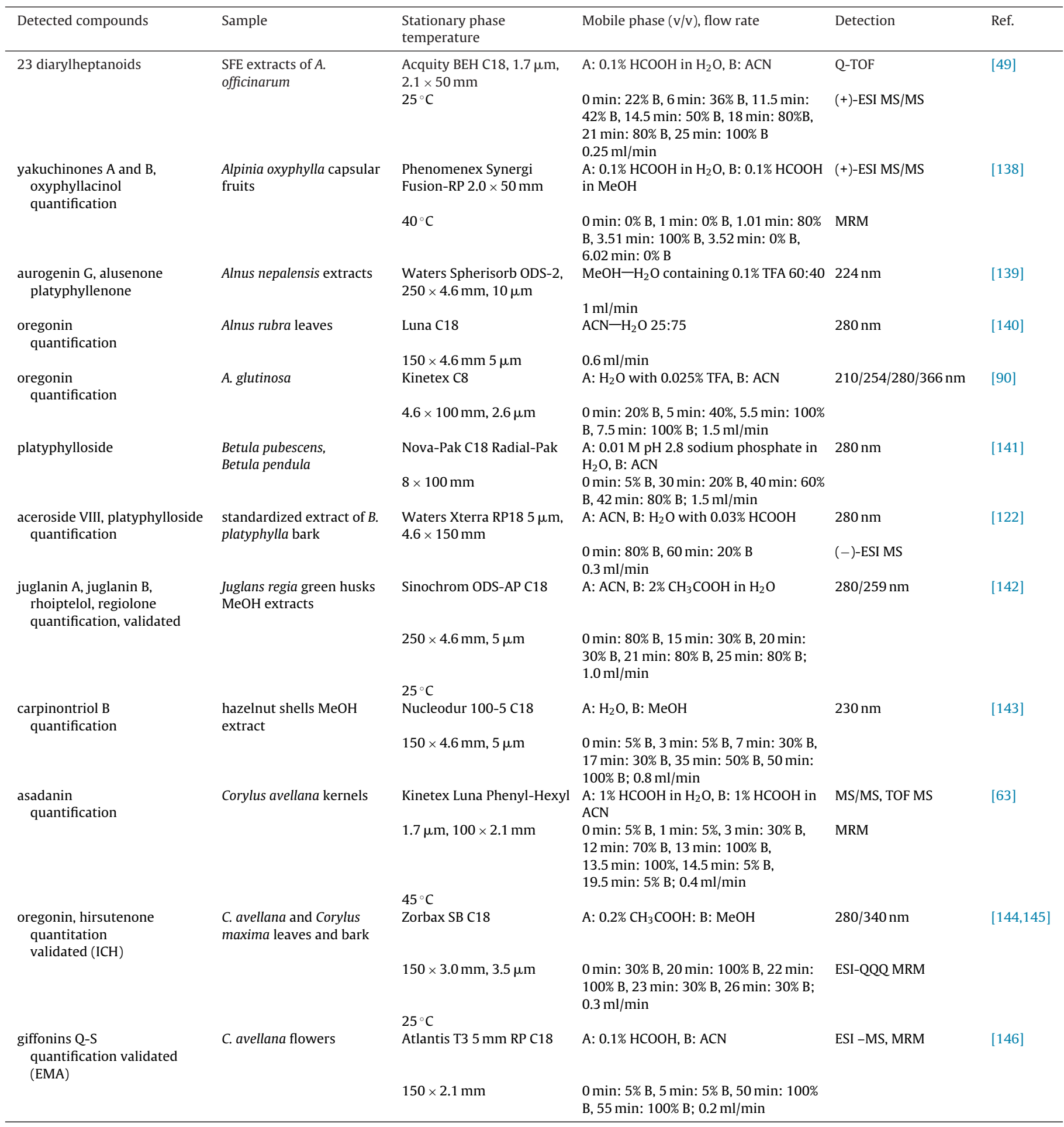

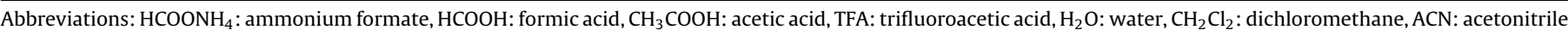

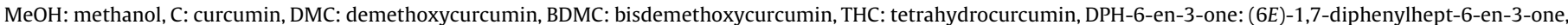

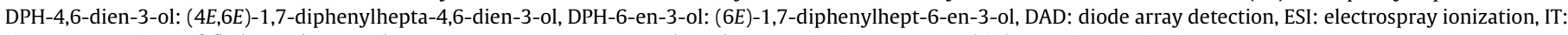
ion trap, TOF: time-of-flight, MS/MS: tandem mass spectrometry, SIM: selected ion monitoring, MRM: multiple reaction monitoring.

[122]. HPLC analysis is usually performed at ambient temperature, however, higher temperatures are also commonly used to reduce analysis time and improve the repeatability of retention times [123]. UV/Vis detection is a prevalent method in HPLC analyses of diarylheptanoids; (for the spectral characteristics see Section 3.1). Selected examples for the application of HPLC coupled to different detection techniques in diarylheptanoid analyses are listed in Table 3.

\subsubsection{HPLC of the diarylheptanoids in Zingiberaceae species}

The literature on HPLC analysis of diarylheptanoids is dominated by the papers on Curcuma and Zingiber species. Plants belonging to these genera contain typically linear diarylheptanoid aglycones, i.e. 
conjugates with sugars do not occur. The polarity of the compounds is determined by the saturation and substitution of the $C_{7}$ chain as well as by the functional groups of the aromatic rings.

Numerous papers focus on the chromatographic separation of curcumin and its demethoxy derivatives. It is known that the highly reactive diketone group of curcuminoids can form intra- and intermolecular hydrogen bonds. It has been assumed that curcuminoids bind irreversibly to the accessible, non-derivatized silanol groups on the silica surface of the stationary phase in C18 columns, thus causing loss of reproducibility [147]. Other authors claimed when citing this work, that due to the very labile characteristics of curcuminoids, C18 columns are preferred for their HPLC analysis [148]. Tønnesen and Karlsen applied a modified amino-bonded column as stationary phase and ethanol as the mobile phase which provided baseline separation of the three curcuminoids [149]. Rouseff stated that the common reversed-phase solvents, water-methanol and water-acetonitrile mixtures did not provide satisfactory resolution on a C18 column, furthermore, tailing did occur, when analyzing curcuminoid pigments in turmeric. Separation of the compounds was obtained by a water-tetrahydrofuran mixture, though the elution order of the three constituents was reversed by the organic modifier to 1 . curcumin, 2 . demethoxycurcumin, and 3. bisdemethoxycurcumin [150], as compared to the elution order of the compounds obtained with a water-acetonitrile solvent system (Fig. 4.).

It has to be mentioned, that residual silanol groups are eliminated in end-capped C18 stationary phases, thus peak tailing effect is reduced. Nevertheless, another crucial condition is the acidity of the eluents applied. A validated C18 HPLC method was developed for the analysis of curcuminoids in turmeric rhizome extracts and in order to study the effect of different ionization suppressing agents such as citric acid, acetic acid, ortho-phosphoric acid, and trifluoroacetic acid on resolution and peak symmetry. Good peak shape and resolution could only be achieved with trifluoroacetic acid due to the partial deactivation of the stationary phase by the highly electronegative fluorine atoms [151]. A reversed-phase UHPLC method with an analysis time of 2 min was developed by Cheng et al. for the simultaneous quantification of curcuminoids in C. longa. The authors suggested that the use of a column with an embedded carbamate group incorporated into the bonded phase prevented peak tailing of the analytes. The elution order of the curcuminoids, however, was reversed on the $\mathrm{C} 18$ column embedded with carbamate groups compared to the conventional C18 column (Fig. 4). Acetic acid, phosphoric acid, and trifluoroacetic acid all gave good resolution and symmetry factor. Increase of the column temperature up to $35^{\circ} \mathrm{C}$ improved the resolution and the symmetry of the peaks [124]. The characteristic HPLC-DAD chromatogram of curcumin, demethoxycurcumin, and bisdemethoxycurcumin can be seen in Fig. 4.

HPLC methods applying a C18 column and isocratic elution have been employed in the quantification of curcuminoids. Bos et al. validated a method to determine curcumin, demethoxycurcumin, and bisdemethoxycurcumin contents in rhizomes of Curcuma species. The chromatographic separation was performed using isocratic elution with a methanol-0.1\% TFA in water-ACN mixture as mobile phase. Baseline separation of the analytes was achieved in a run time of 10 min [152]. Heath et al. developed and validated an isocratic HPLC method to quantify curcumin in plasma and urine samples [153]. Curcumin is reported to have anti-amyloidogenic activity, however, its efficacy is limited due to its low bioavailability. In order to improve the ability of curcumin to cross the blood-brain barrier, it was encapsulated in polylactide-co-glycolicacid nanoparticles. The drug loading capacity and encapsulation efficiency was determined [154]. HPLC with isocratic elution is also used in solubility and stability studies of curcumin preparations [155]. Pan et al. investigated the pharmacokinetic properties of curcumin after i.p. administration to mice using isocratic, reversedphase HPLC assays [156].

Reversed-phase HPLC and UHPLC methods employing C18 columns and gradient solvent systems are universally applied for the determination of curcuminoid contents in diverse Curcuma samples [126,148,157]. The pharmacokinetic parameters of curcumin in healthy human volunteers were investigated after a single oral dose of 10 or $12 \mathrm{~g}$. Free curcumin, its glucuronide, and sulfate conjugates were analyzed in serum samples using a C18 HPLC method with a linear gradient. The LOD of the method was $50 \mathrm{ng} / \mathrm{ml}$, however, free curcumin was detected in only one subject [130].

For the phytochemical characterization of medicinal plant extracts that comprise numerous diarylheptanoids with diverse physical/chemical properties (e.g. glycosides - aglycones), yet contain several structural analogues at the same time, reversed-phase HPLC methods with (multi-step) gradient elution systems and long elution times are needed $[47,60,158]$. Wu et al. optimized a C18 HPLC method with gradient elution to achieve complete separation of A. officinarum diarylheptanoids in $60 \mathrm{~min}$ [86].

The HPLC separation of less polar diarylheptanoids has been performed using normal-phase methods. Estrogenic effect of Curcuma comosa and its two major components, (4E,6E)-1,7-diphenylhepta4,6-dien-3-ol and (6E)-1,7-diphenylhept-6-en-3-ol (Fig. 2.) was reported. To improve the poor solubility, the plant extract and the two diarylheptanoids were formulated into nanoemulsions. A validated, normal-phase HPLC method was used to gain information on the entrapments, drug loading ratios and in situ intestinal absorption rates of diarylheptanoid-nanonemulsions [131]. Su et al. studied the pharmacokinetic profile and organ distribution of the phytoestrogenic compounds from C. comosa hexane extract in rats after i.v. or p.o. administration. The quantities of the analytes were measured by a validated, normal-phase HPLC method [132].

\subsubsection{HPLC study of polyhydroxylated diarylheptanoids}

Plant species belonging to the Betulaceae (and Juglandacee) family contain typically linear or macrocyclic diarylheptanoids conjugated with saccharide moieties $[159,160]$. The polarity of the compounds may be further increased when the constituents are hydroxylated [41,77].

Qualitative and quantitative phytoanalytical studies by RPHPLC were performed on inner bark of Betula pendula and Betula pubescens. Platyphylloside was quantified and found to be present in high amounts in B. pendula and at low levels in B. pubescens [141]. Santamour and Lundgren investigated about 70 taxa of the genus Betula. The tests included RP-HPLC analyses of inner bark extracts on a C18 column with a multi-step gradient in $42 \mathrm{~min}$. Determination of platyphylloside contents helped the identification of the diverse species and verification of interspecific hybrids [161]. The contents of oregonin in A. glutinosa extracts have been determined using isocratic $[140,162]$ and also gradient [59] C18 HPLC methods. Kinetic analyses on aqueous stability of hirsutenone were carried out by a reversed-phase HPLC method [163]. An analogous method was applied to determine hirsutenone concentrations when inclusion complexation with $\beta$-cyclodextrin was performed [164]. Biaryl-type (juglanin B) and diarylethertype (juglanin A, rhoiptelol) macrocyclic diarylheptanoids (Fig. 2) in methanol extracts from the green husks of Juglans regia have been determined simultaneously by a validated HPLC-DAD method. The separation was achieved on a C18 column with gradient elution. Acetonitrile was chosen as the organic eluent, since it gave better resolution, peak shape and stable baseline compared with methanol, while $2 \%(v / v)$ acetic acid in water as the aqueous eluent suppressed the peak tailing and good separation could be achieved [142].

Abedini et al. obtained fractions by CPC from the methanol extract of $A$. glutinosa bark and analyzed the diarylheptanoid com- 
position of those with antimicrobial activity by HPLC. The authors used, contrary to the routine methods, a C8 core-shell column as the stationary phase [90]. In our previous work, the contribution of the individual phenolic compounds including linear diarylheptanoids to the total antioxidant activity of $C$. avellana, Corylus colurna, and Corylus maxima extracts was studied by an HPLC method coupled off-line to the DPPH radical scavenging assay [165].

\subsection{Further LC detection methods}

\subsubsection{HPLC with fluorescence detection (HPLC-FLD)}

Curcuminoids exhibit strong intrinsic fluorescence [166]. The emission spectrum of curcumin is a broad band. The fluorescence maximum is detected around $520-525 \mathrm{~nm}$ in acetonitrile, while in H-bond donors (e.g. alcohols) greater red shifts $\left(\lambda_{\mathrm{Fl}}=550-565\right)$ are exhibited [92,93]. A fluorometric method was developed to determine curcumin in yogurt and mustard samples. Dynamic ranges of the methods covered 4 orders of magnitude concentrations $(0.27-1500 \mathrm{ng} / \mathrm{ml})$, a detection limit as low as $0.08 \mathrm{ng} / \mathrm{ml}$ was achieved [167]. Tønnesen and Karlsen applied their HPLC method with a fluorescence detection mode to determine the content of individual curcuminoids in Curcuma samples. The fluorimetric excitation maximum was at $420 \mathrm{~nm}$, while the emission at $470 \mathrm{~nm}$ resulting in a very low detection limit. Even 20 pg bisdemethoxycurcumin could be detected [149].

\subsubsection{HPLC with evaporative light scattering detection} (HPLC-ELSD)

The diarylheptanoids from the seeds of $A$. longiligulare with estrogenic activity were isolated by HSCCC and preparative HPLC. The contents of the estrogenic diarylheptanoids were determined by HPLC, with a low temperature evaporative light scattering detector in Amomum samples of different origin [85]. For the evaluation of cytotoxic compounds from $C$. avellana stems and leaves, an HPLC-MS method with a photodiode array detector and an evaporative light-scattering detector was employed [54].

\subsubsection{HPLC with electrochemical detection (HPLC-ECD)}

1,7-Diphenylhept-4-en-3-one and its derivatives with hydroxyl substitution on one aromatic ring, as well as diarylheptanoid compounds with a $4^{\prime \prime}$-hydroxy-3"-methoxyphenyl ring from the rhizomes of $A$. officinarum have been separated by a C18 HPLC method and quantified using electrochemical detection (ECD) in the oxidative mode. The HPLC-ECD method showed higher sensitivity than the UV detection for the compounds that could undergo redox reactions. These include compounds possessing electroactive functional groups, such as the hydroxyl or methoxy groups of an aromatic ring [168].

\subsection{Liquid chromatography-mass spectrometry (LC-MS)}

\subsubsection{Ionization interfaces, mass analyzers}

Mass spectrometric (MS) detection coupled to HPLC is the method of choice for the chromatographic separation, qualitative and quantitative phytochemical characterization of plant extracts containing diarylheptanoids.

Atmospheric pressure ionization techniques, such as electrospray ionization (ESI) [122,129,169-171], with both negative [134] and positive $[138,172]$ ion modes have been almost exclusively applied in the MS evaluation of diarylheptanoids. They can be ionized readily and provide simple MS/MS spectra in negative ionization mode, however, the sensitivity of (-)-ESI is low in comparison with (+)-ESI. On the other hand, complex TIC chromatograms and stronger background noise are produced -and adduct ions are also often formed in the positive mode. Further ionization techniques applied for the analysis of curcuminoids are thermospray MS and particle beam MS with electron ionization source [173].

The mass analyzers used in the characterization of diarylheptanoids are time-of-flight (TOF) MS, which enables accurate mass analysis $[50,53,63,136]$, triple-quadrupole (QQQ) MS [75,146,174] that provides additional structural information by the observation of the fragmentation pattern of the target analytes, while quadrupole-time-of-flight (Q-TOF) technique offers exact mass measurement of both precursor and fragment ions $[49,175,176]$. High-resolution ion trap MS analyzer was also applied in the characterization of diarylheptanoid fragmentation in Z. officinale [135].

\subsubsection{Fragmentation behavior of diarylheptanoids}

Unambiguous identification of diarylheptanoids is not possible using LC-MS exclusively, however, structural information can be gained by evaluating the fragmentation of the molecular ions in (high-resolution) tandem or multiple-stage MS analyses. Linear diarylheptanoids can be classified according to differences in the heptane skeletons. Homologs belonging to the same class differ by substitution patterns on the aromatic rings. The fragmentation behavior is diagnostic for diarylheptanoids belonging to different classes of homologous series. As an example, the (-)-ESI and (+)-ESI fragmentation of 1,6-heptadiene-3,5-diones comprising curcuminoids is described, according to the results of Jiang et al. The fragmentation behavior of the three major curcuminoids in quadrupole ion trap MS with positive and negative ESI mode, as well as by sustained off-resonance irradiation (SORI) experiments in a Fourier transform ion cyclotron resonance (FTICR) MS was characterized. Both ion trap and ICR instruments provided the same fragment ions. Diagnostic fragments were identified and the fragmentation schemes were proposed for the three curcuminoids [125,177]. Curcumin (C), demethoxycurcumin (DMC), and bisdemethoxycurcumin (BDMC) possess a common structural moiety of 3- and 5-oxo groups on the 1,6-heptadiene skeleton. In the negative mode, precursor ions at $m / z$ 307, 337, and 367 (ions A) were detected and were assigned to $[\mathrm{M}-\mathrm{H}]^{-}$of BDMC, DMC, and C, respectively (Fig. 5). In the MS/MS spectra of the $[\mathrm{M}-\mathrm{H}]^{-}$ions the base peaks (labelled as B) were the ions $m / z 187,187 / 217$, 217 . The presence of one or two methoxy groups on the aromatic rings resulted in the mass shifts by $30 \mathrm{Da}$ with reference to the $\mathrm{m} / \mathrm{z} 187$ product ion of BDMC. There were two alternative routes, that could lead to the loss of a neutral moiety and as a result, to the formation of product ion B. Rearrangement of B and loss of a $\mathrm{CO}_{2}$ resulted in formation of ions $\mathrm{C}(\mathrm{m} / \mathrm{z} 143,143 / 173,173)$. Product ions $\mathrm{D}(\mathrm{m} / \mathrm{z} 119,119 / 149,149)$ could be formed from both the diketone and the keto-enol form of A (Fig. 6). The authors produced monoacetate derivatives of all the compounds, and additionally the diacetate of curcumin. The fragmentations of these compounds with protected phenolic hydroxyl groups were analyzed in direct infusion (-)-ESI-MS/MS and LC-(-)-ESI-MS/MS experiments, in order to elucidate, whether the enolic hydroxyl groups were accessible for deprotonation, and thus formed the $[\mathrm{M}-\mathrm{H}]^{-}$ions. It was suggested, that both the phenolate and the enolate molecular ions could be detected in (-)-ESI of the curcuminoids. The formation of the phenolate $[\mathrm{M}-\mathrm{H}]^{-}$ion was favored in the presence of two $p$-hydroxyl groups on the aromatic rings, whereas when both $p$ hydroxyl groups were substituted, only the enolate $[\mathrm{M}-\mathrm{H}]^{-}$ion was formed.

The fragmentations of curcuminoids in (+)-ESI-MS/MS were different from the patterns observed for (-)-ESI-MS/MS (Fig. 7). The protonated molecular ions $[\mathrm{M}+\mathrm{H}]^{+}$for BDMC, DMC, and $\mathrm{C}$ were detected at $m / z 309,339$, and 369 (ions E), respectively. It was proposed, that the ionization in positive mode occurred on the $\mathrm{C}_{7}$ chain instead of on the aromatic rings. The diagnostic product ions, all originating from the protonated precursor ion $[\mathrm{M}+\mathrm{H}]^{+}$ were detected for all three curcuminoids. The rearrangement of 
D
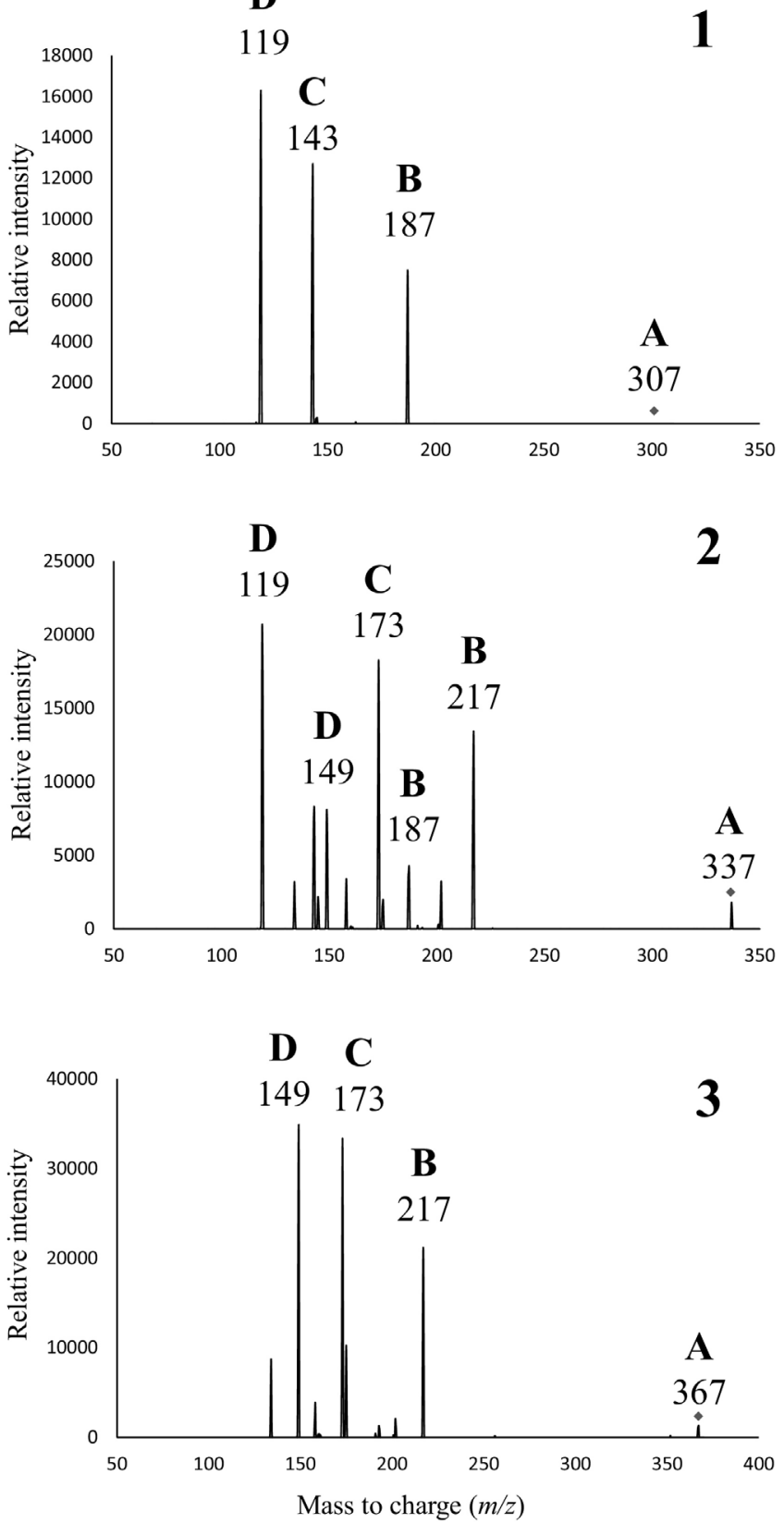

Fig. 5. The (-)-ESI mass spectra of bisdemethoxycurcumin(1), demethoxycurcumin (2), and curcumin (3). The alphabetical notation of the major diagnostic fragment ions refers to the (-)-ESI fragmentation scheme of the compounds shown in Fig. 6. ESI-MS conditions were as follows: Agilent 6410 Triple Quadrupole mass spectrometer with an electrospray ion source in negative ionization mode, temperature: $350{ }^{\circ} \mathrm{C}$, nebulizer pressure: $40 \mathrm{psi}\left(\mathrm{N}_{2}\right)$, drying gas flow rate: $9 \mathrm{l} / \mathrm{min}\left(\mathrm{N}_{2}\right)$, capillary voltage: $4000 \mathrm{~V}$, fragmentor voltage: $120 \mathrm{~V}$, collision energy: $15 \mathrm{eV}$, high purity nitrogen was used as collision gas.

the protonated molecular ions $\mathrm{E}$ and the loss of a 1-hydroxy-3ketocyclobutene moiety yielded product ions $\mathrm{F}(\mathrm{m} / \mathrm{z} 225,255$, and $285)$. Ions $G(m / z 147,147 / 177,177)$ were generated by a 3,4-bond cleavage of E and a neutral loss of a 1-aryl-3-hydroxy-1,3-butadiene moiety. Ions $\mathrm{H}(\mathrm{m} / \mathrm{z} 145,145 / 175,175)$ were produced by an oxo migration in the diketone form of $E$ and a neutral loss of a 3arylcarboxyprop-2-ene moiety [125,177].

The (-)-ESI mass spectra, the (-)-ESI, and (+)-ESI fragmentation schemes of curcumin, demethoxycurcumin, and bisdemethoxycurcumin depicting the major diagnostic fragment ions are shown in Figs. 5-7, respectively.

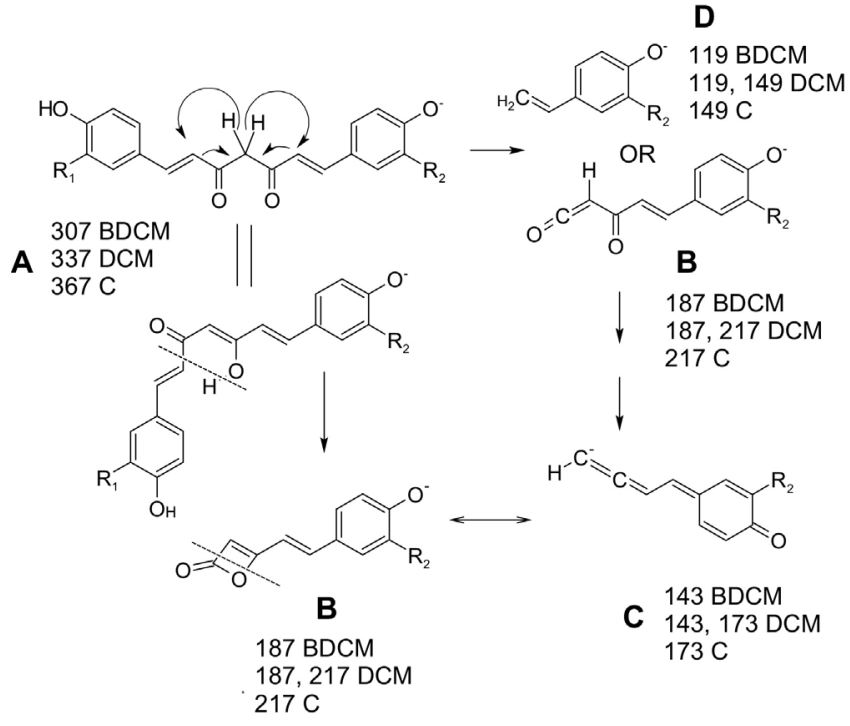

Bisdemethoxycurcumin $(\mathrm{BDCM}): \mathrm{R}_{1}=\mathrm{R}_{2}=\mathrm{H}$ Demethoxycurcumin (DCM): $\mathrm{R}_{1}=\mathrm{H}, \mathrm{R}_{2}=\mathrm{OCH}_{3}$ Curcumin (C): $\mathrm{R}_{1}=\mathrm{R}_{2}=\mathrm{OCH}_{3}$

Fig. 6. The (-)-ESI fragmentation scheme of bisdemethoxycurcumin (BDMC), demethoxycurcumin (DMC), and curcumin (C) depicting the major diagnostic fragment ions, according to Jiang et al. [125,177]. The alphabetical notation of the major fragment ions refers to the (-)-ESI mass spectra of the compounds shown in Fig. 5.

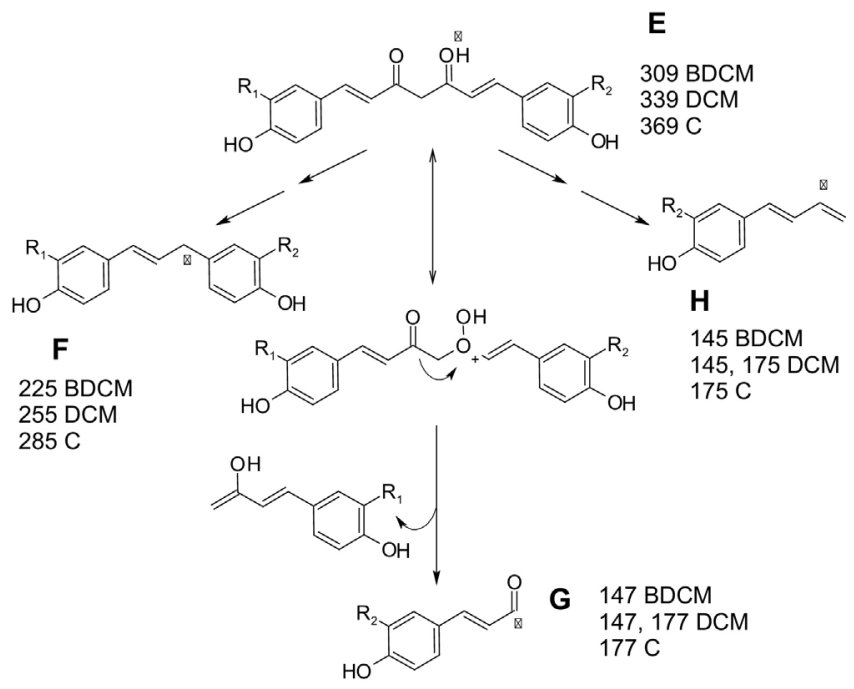

Bisdemethoxycurcumin (BDCM): $\mathrm{R}_{1}=\mathrm{R}_{2}=\mathrm{H}$ Demethoxycurcumin (DCM): $\mathrm{R}_{1}=\mathrm{H}, \mathrm{R}_{2}=\mathrm{OCH}_{3}$ Curcumin (C): $\mathrm{R}_{1}=\mathrm{R}_{2}=\mathrm{OCH}_{3}$

Fig. 7. The (+)-ESI fragmentation scheme of curcuminoids (BDMC: bisdemethoxycurcumin, DMC: demethoxycurcumin, C: curcumin) showing the major fragment ions $[125,177]$.

Neutral losses generated in the fragmentation of diarylheptanoids provide certain structural information. Loss of $18 \mathrm{Da}$ resulting in the product ion $\left[\mathrm{M}+\mathrm{H}-\mathrm{H}_{2} \mathrm{O}\right]^{+}$in the positive ionization mode suggests the presence of a hydroxyl group on the heptane chain instead of on the aromatic rings. When the corresponding ion $\left[\mathrm{M}+\mathrm{H}-2 \mathrm{H}_{2} \mathrm{O}\right]^{+}$with lower abundance is also produced, it is proposed that an oxo group exists on the heptane skeleton rather than a second hydroxyl group, and the product ion is formed by a rearrangement and elimination of $\mathrm{H}_{2} \mathrm{O}$ from the ion $\left[\mathrm{H}+\mathrm{H}-\mathrm{H}_{2} \mathrm{O}\right]^{+}$. The presence of $\left[\mathrm{M}+\mathrm{H}-2 \mathrm{H}_{2} \mathrm{O}\right]^{+}$with higher relative intensity than 
that of $\left[\mathrm{M}+\mathrm{H}-\mathrm{H}_{2} \mathrm{O}\right]^{+}$suggests the presence of a of 3,5-dihydroxy moiety on the alkyl chain instead of on the aromatic rings. The elimination of $16 \mathrm{Da}$ points to the presence of a hydroxyl group on the aromatic rings, while the loss of 60 Da suggests the presence of an acetoxy group. Diarylheptanoids containing 3,5-diacetoxy moieties were described for $Z$. officinale. The product ions $[\mathrm{M}+\mathrm{H}-60]^{+}$ and $[\mathrm{M}+\mathrm{H}-120]^{+}$were commonly detected in their mass spectra, due to the successive loss of two molecules of acetic acid [135,175].

The composition of the saccharide moieties can be assumed by observing neutral losses produced in negative ESI ionization mode during collision-induced dissociation of diarylheptanoids. In case the compounds are glycosylated through a hydroxyl group on the $\mathrm{C}_{7}$ chain, the neutral loss of 180 Da refers to a hexose residue, while that of 150 Da points to a pentose moiety [144,145]. Nevertheless, when the sugar residues are attached to a hydroxyl group on the aromatic rings (e.g. in the cyclic biaryl-type giffonin I), the loss of $162 \mathrm{Da}$ corresponds to a hexose, while that of 132 Da refers to a pentose moiety [146].

The literature regarding ESI fragmentation of diarylheptanoids covers plant extracts, foodstuff as well as a TCM formula. Chromatographic and MS/MS fragmentation characteristics were collected from B. pendula and Betula papyrifera samples [178,179]. Phenolics including linear diarylheptanoid glycosides and aglycones with invitro antioxidant activity were analyzed by LC-DAD-ESI-TOF and LC-ESI-QQQ-MS in C. colurna leaves, bark, catkins and involucres [180]. A multiple-component tablet containing standardized extracts of three medicinal plants was also studied [175]. Chemical composition of fresh, dried, and steamed ginger has been evaluated and compared using TOF-MS [136]. Ma et al. performed the metabolic profiling of greenhouse-grown and in vitro micropropagation derived C. longa and Z. officinale plants [134,169]. Table 4 contains the characteristic molecular ions and fragment ions of several diarylheptanoids obtained by diverse MS techniques.

LC-MS has also been used in stability and pharmacokinetic analyses of diarylheptanoids. Phase 1 metabolism of demethoxy-

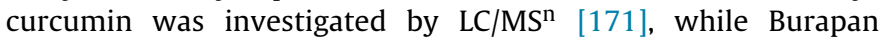
et al. reported recently on new colonic metabolites of curcumin, demethoxycurcumin, and bisdemethoxycurcumin produced by the human intestinal bacterium Blautia sp. [181]. The diarylheptanoids yakuchinones A-B and oxyphyllacinol, as well as their reduced and monoglucuronide metabolites have been investigated by LC-MS/MS in SRM mode in rat plasma after p.o. administration of Alpinia oxyphylla extract. [182]. Autoxidation and horseradish peroxidase-catalyzed oxidation of curcumin and curcumin-glucuronide have been investigated by ESI-MS $[170,183]$.

\subsubsection{Quantitative MS characterization of diarylheptanoids}

Tandem mass spectrometry in selected ion monitoring (SIM) or multiple-reaction monitoring (MRM) modes is frequently applied for the quantification of diarylheptanoids. A quantitative LC-MS method employing an ESI interface was developed to determine the curcuminoid content of food samples, e.g. tablets, candies, and tea. The highest signal intensity for curcuminoids was obtained with a fragmentor voltage of $120 \mathrm{~V}$ and $0.01 \%$ acetic acid in water as aqueous mobile phase. The sample preparation of foodstuff with low curcuminoid content comprised a solid-phase extraction (SPE) pretreatment process, the curcuminoids retained on the C8 cartridges were eluted with ethanol [127]. In our previous work, a validated LC-ESI-MS/MS method was developed using the MRM mode to determine hirsutenone and oregonin contents of $C$. avellana and C. maxima leaf and bark samples. The linearity of the method for hirsutenone was evaluated in the range of $0.01-50 \mu \mathrm{g} / \mathrm{ml}$. Concentrations of $0.002 \mu \mathrm{g} / \mathrm{ml}$ and $0.008 \mu \mathrm{g} / \mathrm{ml}$ were estimated as LOD and LOQ values, respectively $[144,145]$. The content of the cyclic diarylheptanoid alnusone in $C$. avellana male flowers has also been quantified by ESI-QQQ-MS in MRM mode. The method possessed a linear dynamic range between $0.0015-0.020 \mu \mathrm{g} / \mathrm{ml}$ [146]. Asadanin, a bitter tasting cyclic diarylheptanoid has recently been isolated from hazelnut kernels. Sensory analysis of hazelnut samples, followed by LC-MS/MS quantitation of asadanin showed evidence for the box bug (Gonocerus acuteangulatus) infection as the major inductor of asadanin production in hazelnut kernels and, in consequence, as the reason for bitter off-taste development [63]. LC-ESI-MS/MS was applied for the quantification of yakuchinone A together with hexahydrocurcumin in A. officinarum leaves and rhizomes. The LOD was $0.05 \mathrm{ng} / \mathrm{ml}$ for yakuchinone A. The linearity of the method was evaluated in the range of $1-100 \mathrm{ng} / \mathrm{ml}$ and $2-2000 \mathrm{ng} / \mathrm{ml}$ for yakuchinone A and hexahydrocurcumin, respectively [137]. Liu et al. developed a validated MS/MS method to determine curcumin and its metabolite tetrahydrocurcumin (Fig. 2) in rat plasma. The method had an LLOQ of $0.5 \mathrm{ng} / \mathrm{ml}$, which corresponded to $2.5 \mathrm{pg}$ for the $5 \mu \mathrm{l}$ injection volume [129].

\subsection{Less common separation techniques}

\subsubsection{Gas chromatography (GC)}

GC offers high resolution and low detection limit, though it has some limitations in diarylheptanoid analysis, due to the thermal degradability and non-volatile character of the compounds. Jolad et al. analyzed the MS fragmentation patterns of diarylheptanoids in Z. officinale extracts by GC-MS. They detected gingerinone A and tetrahydrocurcumin as well as 3-hydroxy-5-acetoxyheptanes, 3,5diacetoxy-heptanes, and diarylheptanoids containing a 5-methoxy and a 3-keto group. However, the partial or total thermal decomposition of the compounds occurred $[184,185]$. Derivatization of the target analytes is intended to eliminate this disadvantage. Harvey detected ginger constituents - diarylheptanoids (hexahydrocurcumin, demethylhexahydrocurcumin), gingerols, and shogaols as trimethylsilyl derivatives by GC-MS [186]. Phenolic compounds including diarylheptanoids in the sapwood of $B$. pendula were quantified by GC equipped with a flame ionization detector and an HP-5 capillary column, after derivatization with a silylating mixture [187].

\subsubsection{Capillary electrophoresis (CE)}

Lechtenberg et al. separated and quantified the three curcuminoids in Curcuma domestica and Curcuma xanthorrhiza using a capillary zone electrophoresis (CZE) method in an analysis time of less than 5 min [188]. Yuan et al. also developed a validated CZE method with UV detection for the quantitation of curcuminoids. The compounds could be separated within $7 \mathrm{~min}$. The method was applied to determine curcuminoids in urine samples from rats administered curcumin [189]. An optimized CZE method with UV detection was developed for the simultaneous determination of the macrocyclic diarylheptanoids rhoiptelol and juglanins A-C in green walnut husks [190]. Oregonin content in Alnus samples and biological matrices was also quantified using a fast CZE method with UV detection. The optimized conditions allowed as short analysis time as $6 \mathrm{~min}$. Oregonin contents were examined in spiked human serum samples as well as in pig urine and dialysate samples after intragastrical administration of an oregonin-rich fraction from the leaves of $A$. formosana [89]. Watanabe et al. developed a rapid micellar electrokinetic chromatography (MEKC) method using a high molecular mass surfactant for the separation and determination of curcumin, demethoxycurcumin, and bisdemethoxycurcumin in turmeric samples. The method was compared to an isocratic HPLC separation, the detection limits for curcuminoids were $0.02 \mu \mathrm{g} / \mathrm{ml}$ (by HPLC) and $0.1 \mu \mathrm{g} / \mathrm{ml}$ (by MEKC) [191]. A microemulsion electrokinetic chromatography (MEEKC) method was developed for the separation and quantitative analysis of curcuminoids in turmeric 
Table 4

Mass spectrometric features (analysis) of diarylheptanoids.

\begin{tabular}{|c|c|c|c|c|}
\hline Compound & $\begin{array}{l}\text { Negative } \\
\text { ionization, } \\
\text { mass analyzer }\end{array}$ & $\begin{array}{l}\text { Molecular ion } \\
{[\mathrm{M}-\mathrm{H}]^{-}(m / z)}\end{array}$ & Fragment ions $(m / z)$ & Ref. \\
\hline Hirsutenone & ESI QQQ & 327 & $289,254,239,205,121$ & {$[144,145,180]$} \\
\hline 1,7-Bis-(4-hydroxyphenyl)-4,6-heptadien-3-one & ESI QQQ & 293 & $236,211,191,163,135$ & {$[180]$} \\
\hline Centrolobol hexoside & ESI ion trap & 461 & $299,177,121$ & [179] \\
\hline Centrolobol hexosyl-pentoside & ESI ion trap & 593 & $461,299,177,121$ & [179] \\
\hline Centrolobol hexosyl-pentosyl-pentoside & ESI ion trap & 725 & $593,461,299$ & [179] \\
\hline Aceroside VII & ESI QTOF & 461 & n.d. & [178] \\
\hline Aceroside VIII & ESI QTOF & 593 & n.d. & [178] \\
\hline Platyphyllonol-pentoside & ESI QQQ & 445 & $295,189,83$ & [145] \\
\hline Platyphylloside & $\begin{array}{l}\text { ESI ion trap } \\
\text { ESI QTOF }\end{array}$ & 475 & 295 & {$[178,179]$} \\
\hline $\begin{array}{l}\text { (5S)-5-hydroxy-1,7-bis-(4-hydroxyphenyl)-3- } \\
\text { heptanone } \\
\text { 5-O- } \beta \text {-D-apiofuranosyl- }(1 \rightarrow 6)-\beta \text {-D- } \\
\text { glucopyranoside }\end{array}$ & ESI QTOF & 607 & 475 & {$[178]$} \\
\hline $\begin{array}{l}\text { 5-Hydroxy-1-(3,4-dihydroxyphenyl)-7-(4- } \\
\text { hydroxyphenyl)-heptan-3-one }\end{array}$ & ESI QQQ & 329 & $179,165,149,121$ & {$[144,145]$} \\
\hline $\begin{array}{l}\text { 1-(4-Hydroxyphenyl)-7-(3,4- } \\
\text { dihydroxyphenyl)-heptan-3-one-5-O-pentoside }\end{array}$ & ESI QQQ & 461 & $311,189,121$ & [145] \\
\hline Oregonin & ESI QQQ & 477 & $417,335,327,205,125$ & {$[144,145,180]$} \\
\hline Hirsutanonol-hexoside & ESI QQQ & 507 & 327,205 & {$[144,145]$} \\
\hline $\begin{array}{l}\text { 5-Hydroxy-1,7-bis-(4- } \\
\text { hydroxyphenyl)-hept-4-en-3-one-hexoside }\end{array}$ & ESI QQQ & 473 & 293,89 & {$[144,145]$} \\
\hline Bisdemethoxycurcumin & $\begin{array}{l}\text { ion trap } \\
\text { ESI MS/MS }\end{array}$ & 307 & 187,143 & {$[125,177]$} \\
\hline Demethoxycurcumin & $\begin{array}{l}\text { ion trap } \\
\text { ESI MS/MS }\end{array}$ & 337 & $217,187,173$ & {$[125,177]$} \\
\hline Curcumin & $\begin{array}{l}\text { ion trap } \\
\text { ESI MS/MS }\end{array}$ & 367 & 217,173 & {$[125,177]$} \\
\hline Dihydrobisdemethoxycurcumin & $\begin{array}{l}\text { ion trap } \\
\text { ESI MS/MS }\end{array}$ & 309 & $203,189,119$ & [177] \\
\hline Dihydrodemethoxycurcumin & $\begin{array}{l}\text { ion trap } \\
\text { ESI MS/MS }\end{array}$ & 339 & $337,219,189,149,119$ & {$[177]$} \\
\hline Dihydrocurcumin & $\begin{array}{l}\text { ion trap } \\
\text { ESI MS/MS }\end{array}$ & 369 & $233,219,175,149,135$ & {$[177]$} \\
\hline Asadanin & ESI TOF & 343 & $343,283,270,211,193$ & [63] \\
\hline Alnusone & ESI QQQ & 293 & 251,83 & [146] \\
\hline Giffonin I & ESI QQQ & 587 & 293 & {$[146]$} \\
\hline Compound & $\begin{array}{l}\text { Positive } \\
\text { ionization, } \\
\text { mass analyzer }\end{array}$ & $\begin{array}{l}\text { Molecular ion } \\
(m / z)\end{array}$ & Fragment ions $(m / z)$ & Ref. \\
\hline 5-Hydroxy-1,7-bisphenyl-3-heptanone & ESI Q-TOF & 283 & $265,247,149,133,131,117,105,91$ & [49] \\
\hline $\begin{array}{l}\text { 1-Phenyl-7-(4-hydroxy-3-methoxylphenyl)-4-en- } \\
\text { 3-heptanone }\end{array}$ & ESI Q-TOF & 311 & $293,163,161,137,133,105$ & [49] \\
\hline 1-Phenyl-7-(4-hydroxyphenyl)-4-en-3-heptanone & ESI Q-TOF & 281 & $263,161,143,133,107,105$ & [49] \\
\hline $\begin{array}{l}\text { 5-Hydroxy-7-(4-hydroxyphenyl)-1-(4-hydroxy-3- } \\
\text { methoxylphenyl)-3-heptanone }\end{array}$ & ESI Q-TOF & 345 & $327,309,179,177,163,149,137,107$ & [49] \\
\hline $\begin{array}{l}\text { 5-Hydroxy-1-(3,4-dihydroxyphenyl)-7-(4- } \\
\text { hydroxy-3-methoxyphenyl)-3-heptanone }\end{array}$ & ESI Q-TOF & 361 & $343,324,177,137$ & [49] \\
\hline $\begin{array}{l}\text { 5-Hydroxy-1,7-bis(4-hydroxy-3-methoxyphenyl)- } \\
\text { 3-heptanone }\end{array}$ & ESI TOF & $375[\mathrm{M}+\mathrm{H}]^{+}$ & $357\left[\mathrm{M}+\mathrm{H}-\mathrm{H}_{2} \mathrm{O}\right]^{+}, 177,163,145,137$ & [49] \\
\hline $\begin{array}{l}\text { 5-Hydroxy-1-(3,4-dihydroxy-5-methoxyphenyl)- } \\
\text { 7-(4-hydroxy-3-methoxyphenyl)-3-heptanone }\end{array}$ & ESI Q-TOF & $\begin{array}{l}413[\mathrm{M}+\mathrm{Na}]^{+} \\
391[\mathrm{M}+\mathrm{H}]^{+}\end{array}$ & $373\left[\mathrm{M}+\mathrm{H}-\mathrm{H}_{2} \mathrm{O}\right]^{+}, 355\left[\mathrm{M}+\mathrm{H}-2 \mathrm{H}_{2} \mathrm{O}\right]^{+}$ & {$[49,136,175]$} \\
\hline $\begin{array}{l}\text { 3,5-Dihydroxy-1,7-bis(4-hydroxy-3- } \\
\text { methoxyphenyl)-heptane }\end{array}$ & ESI TOF & $399[\mathrm{M}+\mathrm{Na}]^{+}$ & $\begin{array}{l}243,223,197,193,179,177,153,137 \\
359\left[\mathrm{M}+\mathrm{H}-\mathrm{H}_{2} \mathrm{O}\right]^{+}, 341\left[\mathrm{M}+\mathrm{H}-2 \mathrm{H}_{2} \mathrm{O}\right]^{+} \\
163,137\end{array}$ & [136] \\
\hline $\begin{array}{l}\text { 3,5-Dihydroxy-1-(4-hydroxy-3,5- } \\
\text { dimethoxyphenyl)-7-(4-hydroxy-3- } \\
\text { methoxyphenyl)-heptane }\end{array}$ & ESI TOF & $429[\mathrm{M}+\mathrm{Na}]^{+}$ & $389\left[\mathrm{M}+\mathrm{H}-\mathrm{H}_{2} \mathrm{O}\right]^{+}, 371\left[\mathrm{M}+\mathrm{H}-2 \mathrm{H}_{2} \mathrm{O}\right]^{+}$ & {$[136]$} \\
\hline & & & 191,167 & \\
\hline $\begin{array}{l}\text { 3-Acetoxy-5-hydroxy-1,7-bis(3,4- } \\
\text { dihydroxyphenyl)-heptane }\end{array}$ & ESI Q-TOF & $\begin{array}{l}413[\mathrm{M}+\mathrm{Na}]^{+} \\
391[\mathrm{M}+\mathrm{H}]^{+}\end{array}$ & $373\left[\mathrm{M}+\mathrm{H}-\mathrm{H}_{2} \mathrm{O}\right]^{+}, 355\left[\mathrm{M}+\mathrm{H}-2 \mathrm{H}_{2} \mathrm{O}\right]^{+}$ & {$[136,175]$} \\
\hline & & & $\begin{array}{l}313\left[\mathrm{M}+\mathrm{H}-\mathrm{H}_{2} \mathrm{O}-\mathrm{AcOH}\right]^{+} \\
243,193,179,149,131\end{array}$ & \\
\hline $\begin{array}{l}\text { 3-Acetoxy-5-hydroxy-1-(4-hydroxy-3- } \\
\text { methoxyphenyl)-7-(3,4- } \\
\text { dihydroxyphenyl)heptane }\end{array}$ & ESI TOF & $405[\mathrm{M}+\mathrm{H}]^{+}$ & $387\left[\mathrm{M}+\mathrm{H}-\mathrm{H}_{2} \mathrm{O}\right]^{+}, 345[\mathrm{M}+\mathrm{H}-\mathrm{AcOH}]^{+}$ & {$[175]$} \\
\hline & & & 207 & \\
\hline
\end{tabular}


Table 4 (Continued)

\begin{tabular}{|c|c|c|c|c|}
\hline Compound & $\begin{array}{l}\text { Positive } \\
\text { ionization, } \\
\text { mass analyzer }\end{array}$ & $\begin{array}{l}\text { Molecular ion } \\
(m / z)\end{array}$ & Fragment ions $(m / z)$ & Ref. \\
\hline \multirow{2}{*}{$\begin{array}{l}\text { 3-Acetoxy-5-hydroxy-1-(4-hydroxy-3- } \\
\text { methoxyphenyl)-7-(3,4-dihydroxy-5- } \\
\text { methoxyphenyl)heptane }\end{array}$} & ESI TOF & $457[\mathrm{M}+\mathrm{Na}]^{+}$ & $417\left[\mathrm{M}+\mathrm{H}-\mathrm{H}_{2} \mathrm{O}\right]^{+}$ & {$[135,136]$} \\
\hline & & & $\begin{array}{l}375[\mathrm{M}+\mathrm{H}-\mathrm{AcOH}]^{+} \\
357\left[\mathrm{M}+\mathrm{H}-\mathrm{H}_{2} \mathrm{O}-\mathrm{AcOH}\right]^{+} \\
230,179,155,137\end{array}$ & \\
\hline \multirow{2}{*}{$\begin{array}{l}\text { 3-Acetoxy-5-hydroxy-1-(4-hydroxy-3- } \\
\text { methoxyphenyl)-7-(4-hydroxy-3,5- } \\
\text { dimethoxyphenyl)heptane }\end{array}$} & ESI TOF & $471[\mathrm{M}+\mathrm{Na}]^{+}$ & $431\left[\mathrm{M}+\mathrm{H}-\mathrm{H}_{2} \mathrm{O}\right]^{+}$ & {$[135,136]$} \\
\hline & & $467\left[\mathrm{M}+\mathrm{NH}_{4}\right]^{+}$ & $371\left[\mathrm{M}+\mathrm{H}-\mathrm{H}_{2} \mathrm{O}-\mathrm{AcOH}\right]^{+}, 193,163$ & \\
\hline \multirow{2}{*}{$\begin{array}{l}\text { 3,5-Diacetoxy-7-(4-dihydroxy-3-methoxyphenyl)- } \\
\text { 1-(3,4-dihydroxy-5-methoxyphenyl)-heptane }\end{array}$} & ESI TOF & $499[\mathrm{M}+\mathrm{Na}]^{+}$ & $417[\mathrm{M}+\mathrm{H}-\mathrm{AcOH}]^{+}$ & {$[136,175]$} \\
\hline & & $495\left[\mathrm{M}+\mathrm{NH}_{4}\right]^{+}$ & $357[\mathrm{M}+\mathrm{H}-2 \mathrm{AcOH}]^{+}, 217,179,163$ & \\
\hline \multirow{2}{*}{$\begin{array}{l}\text { 3,5-Diacetoxy-1-(4-hydroxy-3,5- } \\
\text { dimethoxyphenyl)-7-(4-hydroxy-3- } \\
\text { methoxyphenyl)-heptane }\end{array}$} & ESI TOF & $513[\mathrm{M}+\mathrm{Na}]^{+}$ & $431[\mathrm{M}+\mathrm{H}-\mathrm{AcOH}]^{+}$ & {$[136,175]$} \\
\hline & & $509\left[\mathrm{M}+\mathrm{NH}_{4}\right]^{+}$ & $\begin{array}{l}371[\mathrm{M}+\mathrm{H}-2 \mathrm{AcOH}]^{+}, 217,193,167 \\
137\end{array}$ & \\
\hline Dihydro-bisdemethoxycurcumin & ESI ion trap & 311 & $225,147,119$ & [177] \\
\hline Dihydrodemethoxycurcumin & ESI ion trap & 341 & $323,245,177,147$ & {$[177]$} \\
\hline Dihydrocurcumin & ESI ion trap & 371 & $353,285,245,177,145$ & {$[177]$} \\
\hline Bisdemethoxycurcumin & $\begin{array}{l}\text { iontrap } \\
\text { ESI-MS/MS }\end{array}$ & 309 & $239,225,215,189,147$ & {$[125,177]$} \\
\hline Demethoxycurcumin & $\begin{array}{l}\text { iontrap } \\
\text { ESI-MS/MS }\end{array}$ & 339 & $269,255,245,177,175,147$ & {$[125,177]$} \\
\hline Curcumin & $\begin{array}{l}\text { iontrap } \\
\text { ESI-MS/MS }\end{array}$ & 369 & $299,285,245,177,175$ & {$[125,177]$} \\
\hline $\begin{array}{l}\text { 7-(4-Hydroxy-3-methoxyphenyl)-1-(4- } \\
\text { hydroxyphenyl)-4,6-heptadien-3-one }\end{array}$ & ESI iontrap & 325 & 219,107 & [177] \\
\hline $\begin{array}{l}\text { 1,7-Bis(4-hydroxy-3-methoxyphenyl)-4,6- } \\
\text { heptadien-3-one }\end{array}$ & ESI iontrap & 355 & $219,177,137$ & [177] \\
\hline $\begin{array}{l}\text { 1-(4-Hydroxy-3-methoxyphenyl)-7-(4-hydroxy- } \\
\text { 3,5-dimethoxyphenyl)-4,6-heptadien-3-one }\end{array}$ & ESI iontrap & 385 & $367,249,189,137$ & [177] \\
\hline
\end{tabular}

capsules and powdered turmeric used as coloring additive in food [192].

\subsubsection{Supercritical fluid chromatography (SFC)}

Supercritical fluid chromatography coupled online to SFE has been applied for the analysis of $C$. longa rhizomes. SFC separation of curcumin was carried out using silica, diol-silica, ODS-silica, and polystyrene-divinylbenzene (PS-DVB) copolymer columns, carbon dioxide as eluent, and methanol as organic modifier. Curcumin was strongly retained on the silica and diol-silica columns, while it was rapidly eluted from the ODS-silica column. Satisfactory separation of curcuminoids was achieved with the PS-DVB copolymer column [52].

\section{Conclusions}

Diarylheptanoid-containing herbal drugs are not only official in Pharmacopoeias but also present in significant amount in dietary supplements. Due to their beneficial biological effects such as anti-inflammatory, estrogenic, cytotoxic, anti-amyloidogenic, and anti-emetic activity, the discovery of new natural diarylheptanoid sources and their phytochemical characterization is of primary importance. The orthogonal analytical toolkit discussed in our review demonstrated that the combination of various separation techniques in conjunction with state-of-the-art spectrometric and spectroscopic methods can overcome the isolation and structural characterization challenges posed by these compounds. However, more efforts are needed in expanding environment-friendly and economic large-scale isolation and purification procedures. The chemical instability and the low bioavailability of diarylheptanoids also necessitate technological advances, in order to improve their drug-like properties. Recent results in the discovery of new diarylheptanoids clearly project that further unique chemical entities will be identified, especially those of cyclic derivatives. The identification of species/genera specific structures and minor representatives will aid and advance the authentication of herbal products and the quality control of dietary supplements.

\section{Acknowledgments}

Financial support from the National Research, Development and Innovation Office (NKFIH) K 120342 is gratefully acknowledged. S. B. thanks the financial support from ÚNKP-16-4 New National Excellence Program of the Ministry of Human Capacities. The authors are thankful to Dr. Anita Zempléni-Tóth and to Dr. Annamária Mészáros for their technical help.

\section{References}

[1] H. Lv, G. She, Naturally occurring diarylheptanoids - a supplementary version, Rec. Nat. Prod. 6 (2012) 321-333.

[2] H. Lv, G. She, Naturally occurring diarylheptanoids, Nat. Prod. Commun. 5 (2010) 1687-1708.

[3] P. Claeson, U.P. Claeson, P. Tuchinda, V. Reutrakul, Occurrence, structure and bioactivity of 1,7-diarylheptanoids, in: Atta-ur-Rahman (Ed.), Studies in Natural Products Chemistry, 26, 2002, pp. 881-908.

[4] G.M. Keserü, M. Nógrádi, The chemistry of natural diarylheptanoids, in: Atta-ur-Rahman (Ed.), Studies in Natural Products Chemistry, 17, 1995, pp. 357-394.

[5] M.E. Alonso-Amelot, Multitargeted bioactive materials of plants in the curcuma genus and related compounds: recent advances, in: Atta-ur-Rahman (Ed.), Studies in Natural Products Chemistry, 47, 2016, pp. $111-200$.

[6] Y.-S. Lin, J.-H. Lin, C.-C. Chang, S.-S. Lee, Tetrahydropyran- and tetrahydrofuran-containing diarylheptanoids from Hedychium coronarium rhizomes, J. Nat. Prod. 78 (2015) 181-187.

[7] M.S. Ali, A.H. Banskota, Y. Tezuka, I. Saiki, S. Kadota, Antiproliferative activity of diarylheptanoids from the seeds of Alpinia blepharocalyx, Biol. Pharm. Bull. 24 (2001) 525-528. 
[8] M.S. Ali, Y. Tezuka, A.H. Banskota, S. Kadota, C.-E. Blepharocalyxins, Three new dimeric diarylheptanoids, and related compounds from the seeds of Alpinia blepharocalyx, J. Nat. Prod. 64 (2001) 491-496.

[9] J.K. Prasain, Y. Tezuka, K. Hase, P. Basnet, H. Dong, T. Namba, S. Kadota, Inhibitory effect of diarylheptanoids on nitric oxide production in activated murine macrophages, Biol. Pharm. Bull. 21 (1998) 371-374.

[10] N. An, H.-w. Zhang, L.-z. Xu, S.-l. Yang, Z.-m. Zou, New diarylheptanoids from the rhizome of Alpinia officinarum Hance, Food Chem. 119 (2010) 513-517.

[11] I. Kontiza, C. Vagias, J. Jakupovic, D. Moreau, C. Roussakis, V. Roussis, Cymodienol and cymodiene: new cytotoxic diarylheptanoids from the sea grass Cymodocea nodosa, Tetrahedron Lett. 46 (2005) 2845-2847.

[12] M.-W. Lee, T. Tanaka, G.-I. Nonaka, I. Nishioka, Hirsunin, an ellagitannin with a diarylheptanoid moiety, from Alnus hirsuta var. microphylla, Phytochemistry 31 (1992) 967-970.

[13] M.H. Kim, K.H. Park, S.R. Kim, K.J. Park, M.H. Oh, J.H. Heo, K.H. Yoon, J. Yin, K.H. Yoon, M.W. Lee, Two new phenolic compounds from the leaves of Alnus sibirica Fisch. ex Turcz, Nat. Prod. Res. 30 (2016) 206-213.

[14] Y.-C. Xiao, J. Lei, M. Liu, M. Yu, J. Ran, J. Xie, W. Li, J. Huang, Three new bisabolocurcumin ethers from the rhizomes of Curcuma longa L, Helv. Chim. Acta. 95 (2012) 327-332.

[15] B.J.C. Silva, A.M.L. Seca, M. do Carmo Barreto, D.C.G.A. Pinto, Recent Breakthroughs in the antioxidant and anti-inflammatory effects of Morella and Myrica species, Int. J. Mol. Sci. 16 (2015) 17160-17180.

[16] M. Tene, H.K. Wabo, P. Kamnaing, A. Tsopmo, P. Tane, J.F. Ayafor, O. Sterner Diarylheptanoids from Myrica arborea, Phytochemistry 54 (2000) 975-978.

[17] Y.-C. Lai, C.-K. Chen, W.-W. Lin, S.-S. Lee, A comprehensive investigation of anti-inflammatory diarylheptanoids from the leaves of Alnus formosana Phytochemistry 73 (2012) 84-94.

[18] Z. Tian, N. An, B. Zhou, P. Xiao, I.S. Kohane, E. Wu, Cytotoxic diarylheptanoid induces cell cycle arrest and apoptosis via increasing ATF3 and stabilizing p53 in SH-SY5Y cells, Cancer Chemoth. Pharm. 63 (2009) 1131-1139.

[19] R. Sawamura, T. Shimizu, Y. Sun, K. Yasukawa, M. Miura, M. Toriyama, S. Motohashi, W. Watanabe, K. Konno, M. Kurokawa, In vitro and in vivo anti-influenza virus activity of diarylheptanoids isolated from Alpinia officinarum, Antivir. Chem. Chemoth. 21 (2010) 33-41.

[20] Y. Yang, K. Kinoshita, K. Koyama, K. Takahashi, S. Kondo, K. Watanabe, Structure-antiemetic-activity of some diarylheptanoids and their analogues, Phytomedicine 9 (2002) 146-152.

[21] N. Thongon, N. Boonmuen, K. Suksen, P. Wichit, A. Chairoungdua, P. Tuchinda, A. Suksamrarn, W. Winuthayanon, P. Piyachaturawat, Selective estrogen receptor modulator (SERM)-like activities of diarylheptanoid a phytoestrogen from Curcuma comosa, in breast cancer cells, pre-osteoblast cells, and rat uterine tissues, J. Agric. Food Chem. 65 (2017) 3490-3496.

[22] Y. Xi, H. Gao, M.U. Callaghan, A.M. Fribley, D.M. Garshott, Z.-X. Xu, Q. Zeng, Y.-L. Li, Induction of BCL2-Interacting killer BIK, is mediated for anti-cancer activity of curcumin in human head and neck squamous cell carcinoma cells, J. Cancer 6 (2015) 327-332.

[23] T. Uto, N.H. Tung, R. Appiah-Opong, A. Aning, O. Morinaga, D. Edoh, A.K Nyarko, Y. Shoyama, Antiproliferative and pro-apoptotic activity of diarylheptanoids isolated from the bark of Alnus japonica in human leukemia cell lines, Am. J. Chin. Med. 43 (2015) 757-767.

[24] O. Lee, J. Kim, Y.W. Choi, M. Lee, G. Park, C. Oh, Efficacy of oregonin investigated by non-invasive evaluation in a B16 mouse melanoma model, Exp. Dermatol. 22 (2013) 832-849.

[25] K.M. Nelson, J.L. Dahlin, J. Bisson, J. Graham, G.F. Pauli, M.A. Walters, The essential medicinal chemistry of curcumin, J. Med. Chem. 60 (2017) 1620-1637.

[26] M. Lee, J.Y. Song, Y.-W. Chin, S.H. Sung, Anti-adipogenic diarylheptanoids from Alnus hirsuta f. sibirica on 3T3-L1 cells, Bioorg. Med. Chem. Lett. 23 (2013) 2069-2073.

[27] M. Kuroyanagi, M. Shimomae, Y. Nagashima, N. Muto, T. Okuda, N. Kawahara, T. Nakane, T. Sano, New diarylheptanoids from Alnus japonica and their antioxidative activity, Chem. Pharm. Bull. 53 (2005) 1519-1523.

[28] T. Matsumoto, S. Nakamura, K. Fujimoto, T. Ohta, K. Ogawa, M. Yoshikawa, E. Onishi, M. Fukaya, H. Matsuda, Structure of diarylheptanoids with antiallergic activity from the rhizomes of Curcuma comosa, J. Nat. Med. 69 (2015) 142-147.

[29] H. Yang, S.H. Sung, J. Kim, Y.C. Kim, Neuroprotective diarylheptanoids from the leaves and twigs of Juglans sinensis against glutamate-Induced toxicity in HT22Cells, Planta Med. 77 (2011) 841-845.

[30] F. Peng, Q. Tao, X. Wu, H. Dou, S. Spencer, C. Mang, L. Xu, L. Sun, Y. Zhao, H. Li, S. Zeng, G. Liu, X. Hao, Cytotoxic, cytoprotective and antioxidant effects of isolated phenolic compounds from fresh ginger, Fitoterapia 83 (2012) 568-585.

[31] D. Yadav, V. Kushwaha, K. Saxena, R. Verma, P.K. Murthy, M.M. Gupta, Diarylheptanoid compounds from Alnus nepalensis express in vitro and in vivo antifilarial activity, Acta Trop. 128 (2013) 509-517.

[32] A. Suksamrarn, M. Ponglikitmongkol, K. Wongkrajang, A. Chindaduang, S. Kittidanairak, A. Jankam, B. -e. Yingyongnarongkul, N. Kittipanumat, R. Chokchaisiri, P. Khetkam, P. Piyachaturawat, Diarylheptanoids, new phytoestrogens from the rhizomes of Curcuma comosa: isolation, chemical modification and estrogenic activity evaluation, Bioorgan. Med. Chem. 16 (2008) 6891-6902

[33] K. Ara, A.H.M.M. Rahman, C.M. Hasan, M.N. Iskander, Y. Asakawa, D.N. Quang, M.A. Rashid, Macrocyclic diarylheptanoids from Garuga pinnata, Phytochemistry 67 (2006) 2659-2662.
[34] H. Akazawa, Y. Fujita, N. Banno, K. Watanabe, Y. Kimura, A. Manosroi, J Manosroi, T. Akihisa, Three new cyclic diarylheptanoids and other phenolic compounds from the bark of Myrica rubra and their melanogenesis inhibitory and radical scavenging activities, J. Oleo Sci. 59 (2010) 213-221.

[35] T. Akihisa, A. Takeda, H. Akazawa, T. Kikuchi, S. Yokokawa, M. Ukiya, M Fukatsu, K. Watanabe, Melanogenesis-Inhibitory and cytotoxic activities of diarylheptanoids from Acer nikoense bark and their derivatives, Chem. Biodivers. 9 (2012) 1475-1489.

[36] M. Novaković, M. Stanković, I. Vučković, N. Todorović, S. Trifunović, V. Tešević, V. Vajs, S. Milosavljević, Diarylheptanoids from Alnus glutinosa bark and their chemoprotective effect on human lymphocytes DNA, Planta Med. 79 (2013) 499-505

[37] S.R.M. Ibrahim, M.A. Fouad, A. Abdel-Lateff, T. Okino, G.A. Mohamed, Alnuheptanoid A: a new diarylheptanoid derivative from Alnus japonica, Nat. Prod. Res. 28 (2014) 1765-1771.

[38] S.R.M. Ibrahim, G.A. Mohamed, A.I.M. Khedr, B.M. Aljaeid, B. Alnuheptanoid, A new cyclic diarylheptanoid from Alnus japonica stem bark, Rec. Nat. Prod. 10 (2016) 362-368

[39] Y. Sun, K. Tabata, H. Matsubara, S. Kitanaka, T. Suzuki, K. Yasukawa, New cytotoxic diarylheptanoids from the rhizomes of Alpinia officinarum, Planta Med. 74 (2008) 427-431.

[40] H. Fuchino, S. Konishi, T. Satoh, A. Yagi, K. Saitsu, T. Tatsumi, N. Tanaka, Chemical evaluation of Betula species in Japan. II. constituents of Betula platyphylla var. japonica, Chem. Pharm. Bull. 44 (1996) 1033-1038.

[41] M. Masullo, A Cerulli, B. Olas, C. Pizza, S. Piacente, A.-I. Giffonins, Antioxidant cyclized diarylheptanoids from the leaves of the hazelnut tree (Corylus avellana), source of the italian PGI product Nocciola di Giffoni, J. Nat. Prod. 78 (2015) 17-25.

[42] S.-D. Chen, J.-T. Gao, J.-G. Liu, B. Liu, R.-Z. Zhao, C.-J. Lu, Five new diarylheptanoids from the rhizomes of Curcuma kwangsiensis and their antiproliferative activity, Fitoterapia 102 (2015) 67-73.

[43] J. Li, F. Zhao, M.Z. Li, L.X. Chen, F. Qiu, Diarylheptanoids from the rhizomes of Curcuma kwangsiensis, J. Nat. Prod. 73 (2010) 1667-1671.

[44] M. Yoshimura, S. Yamakami, Y. Amakura, T. Yoshida, Diarylheptanoid sulfates and related compounds from Myrica rubra bark, J. Nat. Prod. 75 (2012) 1798-1802.

[45] J. Tao, T. Morikawa, I. Toguchida, S. Ando, H. Matsuda, M. Yoshikawa, Inhibitors of nitric oxide production from the bark of Myrica rubra: structures of new biphenyl type diarylheptanoid glycosides and taraxerane type triterpene, Bioorgan. Med. Chem. 10 (2002) 4005-4012.

[46] M.A. Beniddir, P. Grellier, P. Rasoanaivo, P.M. Loiseau, C. Bories, V. Dumontet F. Guéritte, M. Litaudon, Diarylheptanoid glucosides from Pyrostria major and their antiprotozoal activities, Eur. J. Org. Chem. 2012 (2012) 1039-1046.

[47] C. Gilli, E. Orlowska, D. Kaiser, J. Steyrer, A. Rathgeb, E. Lorbeer, L. Brecker, J. Schinnerl, Diarylheptanoids, flavonoids and other constituents from two neotropical Renealmia species (Zingiberaceae), Biochem. Syst. Ecol. 56 (2014) 178-184

[48] M. Herrero, J.A. Mendiola, A. Cifuentes, E. Ibáñez, Supercritical fluid extraction: recent advances and applications, J. Chromatogr. A. 1217 (2010) 2495-2511.

[49] J. Luo, W. Rui, M. Jiang, Q. Tian, X. Ji, Y. Feng, Separation and identification of diarylheptanoids in supercritical fluid extract of Alpinia officinarum by UPLC-MS-MS, J. Chromatogr. Sci. 48 (2010) 795-801.

[50] J. Švarc-Gajić, A. Cvetanović, A. Segura-Carretero, I.B. Linares, P. Mašković, Characterisation of ginger extracts obtained by subcritical water, J. Supercrit. Fluids. 123 (2017) 92-100.

[51] A.L. Chassagnez-Méndez, N.T. Machado, M.E. Araujo, J.G. Maia, M.A.A. Meireles, Supercritical $\mathrm{CO}_{2}$ extraction of curcumins and essential oil from the rhizomes of turmeric (Curcuma longa L.), Ind. Eng. Chem. Res. 39 (2000) 4729-4733.

[52] M.M. Sanagi, U.K. Ahmad, R.M. Smith, Application of supercritical fluid extraction and chromatography to the analysis of turmeric, J. Chromatogr. Sci. 31 (1993) 20-25.

[53] J. Hu, Z. Guo, M. Glasius, K. Kristensen, L. Xiao, X. Xu, Pressurized liquid extraction of ginger (Zingiber officinale Roscoe) with bioethanol: an efficient and sustainable approach, J. Chromatogr. A 1218 (2011) 5765-5773.

[54] A. Gallego, I. Metón, IV. Baanante, J. Ouazzani, E. Adelin, J Palazon, M. Bonfill, E. Moyano, Viability-reducing activity of Coryllus avellana L. extracts against human cancer cell lines, Biomed. Pharmacother. 89 (2017) 565-572.

[55] F. Sahne, M. Mohammadi, G.D. Najafpour, A.A. Moghadamnia, Enzyme-assisted ionic liquid extraction of bioactive compound from turmeric (Curcuma longa L.): Isolation, purification and analysis of curcumin, Ind. Crops Prod. 95 (2017) 686-694

[56] J. Xu, W. Wang, H. Liang, Q. Zhang, Q. Li, Optimization of ionic liquid based ultrasonic assisted extraction of antioxidant compounds from Curcuma longa L. using response surface methodology, Ind. Crops Prod. 76 (2015) 487-493.

[57] P.S. Wakte, B.S. Sachin, A.A. Patil, D.M. Mohato, T.H. Band, D.B. Shinde, Optimization of microwave, ultra-sonic and supercritical carbon dioxide assisted extraction techniques for curcumin from Curcuma longa, Sep. Purif. Technol. 79 (2011) 50-55.

[58] S. Li, W. Yuan, G. Deng, P. Wang, P. Yang, B.B. Aggarwal, Chemical composition and product quality control of turmeric (Curcuma longa L.), Pharm. Crop. 2 (2011) 28-54.

[59] L. Roze, O. Bikovens, G. Telysheva, Determination and separation of diarylheptanoids from alder growing in Latvia, Proceedings of the 8th 
International Scientific and Practical Conference (2017) 329-332 (ISBN 978-9984-44-070-5, vol. 1, Rēzekne, 2011)

[60] G. Tang, X. Dong, X. Huang, X.-J. Huang, H. Liu, Y. Wang, W.-C. Ye, L. Shi, A natural diarylheptanoid promotes neuronal differentiation via activating ERK and PI3K-AKT dependent pathways, Neuroscience 303 (2015) 389-401.

[61] V. Keeratinijakal, S. Kongkiatpaiboon, Distribution of phytoestrogenic diarylheptanoids and sesquiterpenoids components in Curcuma comosa rhizomes and its related species, Rev. Bras. Farmacogn. 27 (2017) 290-296.

[62] S.H. Kim, J.H. Park, T.B. Kim, H.H. Lee, K.Y. Lee, Y.C. Kim, S.H. Sung, Inhibition of antigen-induced degranulation by aryl compounds isolated from the bark of Betula platyphylla in RBL-2H3 cells, Bioorg. Med. Chem. Lett. 20 (2010) 2824-2827.

[63] B. Singldinger, A. Dunkel, T. Hofmann, The cyclic diarylheptanoid asadanin As the main contributor to the bitter off-taste in hazelnuts (Corylus avellana L.), J. Agric. Food Chem. 65 (2017) 1677-1683.

[64] V. Mshvildadze, J. Legault, S. Lavoie, C. Gauthier, A. Pichette, Anticance diarylheptanoid glycosides from the inner bark of Betula papyrifera, Phytochemistry 68 (2007) 2531-2536.

[65] G.K. Jayaprakasha, G.A. Nagana Gowda, S. Marquez, B.S. Patil, Rapid separation and quantitation of curcuminoids combining pseudo two-dimensional liquid flash chromatography and NMR spectroscopy, J. Chromatogr. B Analyt. Technol. Biomed. Life Sci. 937 (2013) 25-32.

[66] J. Yin, K. Kouda, Y. Tezuka, Q. Le Tran, T. Miyahara, Y. Chen, S. Kadota, New diarylheptanoids from the rhizomes of Dioscorea spongiosa and their antiosteoporotic activity, Planta Med. 70 (2004) 54-58.

[67] J.-W. Nam, E.-K. Seo, Identification of six new minor diarylheptanoids from the seeds of Alpinia katsumadai, Helv. Chim. Acta 96 (2013) 1670-1680

[68] D.L. Yao, C.H. Zhang, J. Luo, M. Jin, M.S. Zheng, J.M. Cui, J.K. Son, G. Li, Chemical constituents from the leaves of Juglans mandshurica, Arch. Pharm. Res. 38 (2015) 480-484.

[69] R. Kaewamatawong, P. Boonchoong, N. Teerawatanasuk, Diarylheptanoids from Curcuma comosa, Phytochem. Lett. 2 (2009) 19-21.

[70] Y.-F. Yu, Q. Lu, L. Guo, R.-Q. Mei, H.-X. Liang, D.-Q. Luo, Y.-X. Cheng, Myricananone and myricananadiol two new cyclic 'diarylheptanoids' from the roots of Myrica nana, Helv. Chim. Acta. 90 (2007) 1691-1696.

[71] J.K. Prasain, Y. Tezuka, J.X. Li, K. Tanaka, P. Basnet, H. Dong, T. Namba, S. Kadota, Six novel diarylheptanoids bearing chalcone or flavanone moiety from the seeds of Alpinia blepharocalyx, Tetrahedron 53 (1997) 7833-7842.

[72] F.-L. Wang, J.-G. Luo, X.-B. Wang, L.-Y. Kong, A pair of sulfonated diarylheptanoid epimers from Kaempferia galanga, Chin. J. Nat. Med. 11 (2013) 171-176.

[73] Y. Hori, T. Miura, Y. Hirai, M. Fukumura, Y. Nemoto, K. Toriizuka, Y. Ida, Pharmacognostic studies on ginger and related drugs-part 1: five sulfonated compounds from Zingiberis rhizome (Shokyo), Phytochemistry 62 (2003) 613-617

[74] N. An, L.-Z. Xu, Z.-M. Zou, S.-L. Yang, Diarylheptanoids from Alpinia officinarum, J. Asian Nat. Prod. Res. 8 (2006) 637-641.

[75] C. Heffernan, M. Ukrainczyk, R.K. Gamidi, B.K. Hodnett, Å.C. Rasmuson, Extraction and purification of curcuminoids from crude curcumin by a combination of crystallization and chromatography, Org. Process Res. Dev. 21 (2017) 821-826.

[76] F. Hanawa, M. Shiro, Y. Hayashi, Heartwood constituents of Betula maximowicziana, Phytochemistry 45 (1997) 589-595.

[77] M. Masullo, V. Cantone, A. Cerulli, G. Lauro, F. Messano, G.L. Russo, C. Pizza, G. Bifulco, S. Piacente, J.-P. Giffonins, Highly hydroxylated cyclized diarylheptanoids from the leaves of Corylus avellana cultivar tonda di giffoni, J. Nat. Prod. 78 (2015) 2975-2982.

[78] M. Novaković, M. Pešić, S. Trifunović, I. Vučković, N. Todorović, A Podolski-Renić, J. Dinić, S. Stojković, V. Tešević, V. Vajs, S. Milosavljević, Diarylheptanoids from the bark of black alder inhibit the growth of sensitive and multi-drug resistant non-small cell lung carcinoma cells, Phytochemistry 97 (2014) 46-54.

[79] B.H. Clampitt, J.W. Callis, Photochemical isomerization of cinnamic acid in aqueous solutions, J. Phys. Chem. 66 (1962) 201-204.

[80] D.S. Noyce, P.A. King, F.B. Kirby, W.L. Reed, The kinetics of the acid-catalyzed isomerization of cis-cinnamic acid, J. Am. Chem. Soc. 84 (1962) 1632-1635.

[81] S. Kadota, Y. Tezuka, J.K. Prasain, M.S. Ali, A.H. Banskota, Novel diarylheptanoids of Alpinia blepharocalyx, Curr. Top. Med. Chem. 3 (2003) 203-225.

[82] Y. Tezuka, M.S. Ali, A.H. Banskota, S. Kadota, Blepharocalyxins C-E: three novel antiproliferative diarylheptanoids from the seeds of Alpinic blepharocalyx, Tetrahedron Lett. 41 (2000) 5903-5907.

[83] J.-W. Nam, G.-Y. Kang, A.-R. Han, D. Lee, Y.-S. Lee, E.-K. Seo, Diarylheptanoids from the seeds of Alpinia katsumadai as heat shock factor 1 inducers, J. Nat. Prod. 74 (2011) 2109-2115.

[84] S.-H. Dong, D. Nikolić, C. Simmler, F. Qiu, R.B. van Breemen, D.D. Soejarto, G.F. Pauli, S.-N. Chen, Diarylheptanoids from Dioscorea villosa (Wild yam), J. Nat. Prod. 75 (2012) 2168-2177.

[85] H. Ying, J. Liu, Q. Du, Analysis and determination of oestrogen-active compounds in fructus amomi by the combination of high-speed counter-current chromatography and high performance liquid chromatography, J. Chromatogr. B Analyt. Technol. Biomed. Life Sci. 958 (2014) 36-42

[86] X. Wu, Z. Chao, C. Wang, L. Yu, Separation of chemical constituents from three plant medicines by counter-current chromatography using a three-phase solvent system at a novel ratio, J. Chromatogr. A. 1384 (2015) $107-114$

[87] X. Xiao, X. Si, X. Tong, G. Li, Preparation of flavonoids and diarylheptanoid from Alpinia katsumadai hayata by microwave-assisted extraction and high-speed counter-current chromatography, Sep. Purif. Technol. 81 (2011) 265-269.

[88] S.S. Lim, M.Y. Lee, H.R. Ahn, S.J. Choi, J.-Y. Lee, S.H. Jung, Preparative isolation and purification of antioxidative diarylheptanoid derivatives from Alnus japonica by high-speed counter-current chromatography, J. Sep. Sci. 34 (2011) 3344-3352.

[89] C.-H. Kuo, C.-W. Lee, Y.-C. Lai, S.-S. Lee, Determination of oregonin in Alnus plants and biological samples by capillary electrophoresis, J. Pharm. Biomed. Anal. 47 (2008) 195-200.

[90] A. Abedini, S. Chollet, A. Angelis, N. Borie, J.-M. Nuzillard, A.-L. Skaltsounis, R. Reynaud, S.C. Gangloff, J.-H. Renault, J. Hubert, Bioactivity-guided identification of antimicrobial metabolites in Alnus glutinosa bark and optimization of oregonin purification by Centrifugal Partition Chromatography, J. Chromatogr. B Analyt. Technol. Biomed. Life Sci. 1029-1030 (2016) 121-127.

[91] F. Zsila, Z. Bikádi, M. Simonyi, Unique, pH-dependent biphasic band shape of the visible circular dichroism of curcumin-serum albumin complex, Biochem. Biophys. Res. Commun. 301 (2003) 776-782.

[92] C.F. Chignell, P. Bilski, K.J. Reszka, A.G. Motten, R.H. Sik, T.A. Dahl, Spectral and photochemical properties of curcumin, Photochem. Photobiol. 59 (1994) 295-302.

[93] L. Nardo, R. Paderno, A. Andreoni, M. Másson, T. Haukvik, H.H. Tønnesen, Role of H-bond formation in the photoreactivity of curcumin, Spectroscopy 22 (2008) 187-198.

[94] Y. Erez, R. Simkovitch, S. Shomer, R. Gepshtein, D. Huppert, Effect of acid on the ultraviolet-Visible absorption and emission properties of curcumin, J. Phys. Chem. A. 118 (2014) 872-884.

[95] ASTA Analytical Methods, curcumin content of turmeric spice and oleoresins, method 18.0, revised October 2004.

[96] C.E. Green, S.L. Hibbert, Y.A. Bailey-Shaw, L.A.D. Williams, S. Mitchell, E. Garraway, Extraction, processing, and storage effects on curcuminoids and oleoresin yields from Curcuma longa L. grown in Jamaica, J. Agric. Food Chem. 56 (2008) 3664-3670.

[97] Turmeric rhizome monograph, European Pharmacopoeia (9th ed.), European Directorate for the Quality of Medicines (EDQM), Strasbourg, France, 2017.

[98] Javanese turmeric monograph, European Pharmacopoeia (9th ed.), European Directorate for the Quality of Medicines (EDQM), Strasbourg, France, 2017.

[99] K. Ahmed, Y. Li, D.J. McClements, H. Xiao, Nanoemulsion- and emulsion-based delivery systems for curcumin: encapsulation and release properties, Food Chem. 132 (2012) 799-807.

[100] K. Tanaka, Y. Kuba, T. Sasaki, F. Hiwatashi, K. Komatsu, Quantitation of curcuminoids in Curcuma rhizome by near-infrared spectroscopic analysis, J. Agric. Food Chem. 56 (2008) 8787-8792.

[101] S. Kasemsumran, V. Keeratinijakal, W. Thanapase, Y. Ozaki, Near infrared quantitative analysis of total curcuminoids in rhizomes of Curcuma longa by moving window partial least squares regression, J. Near Infrared Spectrosc. 18 (2010) 263-269

[102] M. Morihara, N. Sakurai, T. Inoue, K. Kawai, M. Nagai, Two novel diarylheptanoid glucosides from Myrica gale var. tomentosa and absolute structure of plane-Chiral Galeon, Chem. Pharm. Bull. 45 (1997) 820-823.

[103] S.-S. Jing, Y. Wang, Y.-M. Yan, X. Li, X.-J. Li, C.-C. Zhao, J.-C. Sun, P.-Y. Qiu, S.-L. Man, W.-Y. Gao, Diocollettines A, an unusual tricyclic diarylheptanoid derivative from the rhizomes of Dioscorea collettii, Tetrahedron Lett. 57 (2016) 3215-3217.

[104] A. Cerulli, G. Lauro, M. Masullo, V. Cantone, B. Olas, B. Kontek, F. Nazzaro, G. Bifulco, S. Piacente, Cyclic diarylheptanoids from Corylus avellana green leafy covers: determination of their absolute configurations and evaluation of their antioxidant and antimicrobial activities, J. Nat. Prod. 80 (2017) 1703-1713.

[105] G. Islas-Gonzalez, M. Bois-Choussy, J. Zhu, From central to planar chirality, the first example of atropenantioselective cycloetherification, Org. Biomol. Chem. 1 (2003) 30-32.

106] V. Costantino, E. Fattorusso, A. Mangoni, C. Perinu, R. Teta, E. Panza, A. Ianaro, Tedarenes a and B: structural and stereochemical analysis of two new strained cyclic diarylheptanoids from the marine sponge Tedania ignis, J. Org. Chem. 77 (2012) 6377-6383.

[107] A. Yokosuka, Y. Mimaki, H. Sakagami, Y. Sashida, New diarylheptanoids and diarylheptanoid glucosides from the rhizomes of Tacca chantrieri and their cytotoxic activity, J. Nat. Prod. 65 (2002) 283-289.

[108] W. Li, S. Wang, J. Feng, Y. Xiao, X. Xue, H. Zhang, Y. Wang, X. Liang, Structure elucidation and NMR assignments for curcuminoids from the rhizomes of Curcuma longa, Magn. Reson. Chem. 47 (2009) 902-908

[109] M. Novaković, M. Stanković, I. Vučković, N. Todorović, S. Trifunović, D. Apostolović, B. Mandić, M. Veljić, P. Marin, V. Tešević, V. Vajs, S. Milosavljević, Diarylheptanoids from green alder bark and their potential for DNA protection, Chem. Biodivers. 11 (2014) 872-885.

[110] H. Matsuda, T. Morikawa, J. Tao, K. Ueda, M. Yoshikawa, Bioactive constituents of Chinese natural medicines. VII. 1) inhibitors of degranulation in RBL-2H3Cells and absolute stereostructures of three new diarylheptanoid glycosides from the bark of Myrica rubra, Chem. Pharm. Bull. 50 (2002) 208-215. 
[111] J.K. Prasain, J.-X. Li, Y. Tezuka, K. Tanaka, P. Basnet, H. Dong, T. Namba, S. Kadota, H. Calyxin, Epicalyxin H, and blepharocalyxins A and B, novel diarylheptanoids from the seeds of Alpinia blepharocalyx, J. Nat. Prod. 61 (1998) 212-216.

[112] Á.M. Móricz, P.G. Ott, T.T. Häbe, A. Darcsi, A. Böszörményi, Á. Alberti, D. Krüzselyi, P. Csontos, S. Béni, G.E. Morlock, Effect-Directed discovery of bioactive compounds followed by highly targeted characterization, isolation and identification, exemplarily shown for Solidago virgaurea, Anal. Chem. 88 (2016) 8202-8209.

[113] C.A. Slabber, C.D. Grimmer, R.S. Robinson, Solution conformations of curcumin in DMSO, J. Nat. Prod. 79 (2016) 2726-2730.

[114] H.H. Tønnesen, A.-L. Grislingaas, J. Karlsen, Studies on curcumin and curcuminoids XIX. Evaluation of thin-layer chromatography as a method for quantitation of curcumin and curcuminoids, Z. Lebensm. Unters. Forsch. 193 (1991) 548-550.

[115] H.B. Rasmussen, S.B. Christensen, L.P. Kvist, A. Karazmi, A. Simple, Efficient separation of the curcumins, the antiprotozoal constituents of Curcuma longa, Planta Med. 66 (2000) 396-398.

[116] A.P. Gupta, M.M. Gupta, S. Kumar, Simultaneous determination of curcuminoids in Curcuma samples using high performance thin layer chromatography, J. Liq. Chromatogr. Relat. Technol. 22 (1999) 1561-1569.

[117] V. Pathania, A.P. Gupta, B. Singh, Improved HPTLC method for determination of curcuminoids from Curcuma longa, J. Liq. Chromatogr. Relat. Technol. 29 (2006) 877-887.

[118] M.J. Ansari, S. Ahmad, K. Kohli, J. Ali, R.K. Khar, Stability-indicating HPTLC determination of curcumin in bulk drug and pharmaceutical formulations, J. Pharm. Biomed. Anal. 39 (2005) 132-138.

[119] M. Paramasivam, R. Poi, H. Banerjee, A. Bandyopadhyay, High-performance thin layer chromatographic method for quantitative determination of curcuminoids in Curcuma longa germplasm, Food Chem. 113 (2009) 640-644.

[120] D. Yadav, S.C. Singh, R.K. Verma, K. Saxena, R. Verma, P.K. Murthy, M.M. Gupta, Antifilarial diarylheptanoids from Alnus nepalensis leaves growing in high altitude areas of Uttarakhand, India, Phytomedicine 20 (2013) 124-132

[121] D. Yadav, M.M. Gupta, Simultaneous quantification of diarylheptanoids in Alnus nepalensis using a validated HPTLC method, J. Chromatogr. Sci. 58 (2014) 905-910.

[122] K.Y. Lee, E.J. Jeong, J. Huh, N. Cho, T.B. Kim, B.J. Jeon, S.H. Kim, H.P. Kim, S.H. Sung, Cognition-enhancing and neuroprotective activities of the standardized extract of Betula platyphylla bark and its major diarylheptanoids, Phytomedicine 19 (2012) 1315-1320.

[123] E. de Rijke, P. Out, W.M.A. Niessen, F. Ariese, C. Gooijer, U.T.A. Brinkman, Analytical separation and detection methods for flavonoids, J. Chromatogr. A. 1112 (2006) $31-63$.

[124] J. Cheng, K. Weijun, L. Yun, W. Jiabo, W. Haitao, L. Qingmiao, X. Xiaohe, Development and validation of UPLC method for quality control of Curcume longa Linn.: Fast simultaneous quantitation of three curcuminoids, J. Pharm. Biomed. Anal. 53 (2010) 43-49.

[125] H. Jiang, Á. Somogyi, N.E. Jacobsen, B.N. Timmermann, D.R. Gang, Analysis of curcuminoids by positive and negative electrospray ionization and tandem mass spectrometry, Rapid Commun. Mass Spectrom. 20 (2006) 1001-1012.

[126] E. Mudge, M. Chan, S. Venkataraman, P.N. Brown, Curcuminoids in turmeric roots and supplements: method optimization and validation, Food Anal. Method. 9 (2016) 1428-1435.

[127] K. Inoue, S. Hamasaki, Y. Yoshimura, M. Yamada, M. Nakamura, Y. Ito, H. Nakazawa, Validation of LC/electrospray-MS for determination of majo curcuminoids in foods, J. Liq. Chromatogr. Relat. Technol. 26 (2003) 53-62.

[128] Y.-J. Wang, M.-H. Pan, A.-L. Cheng, L.-I. Lin, Y.-S. Ho, C.-Y. Hsieh, J.-K. Lin, Stability of curcumin in buffer solutions and characterization of its degradation products, J. Pharm. Biomed. Anal. 15 (1997) 1867-1876.

[129] A. Liu, H. Lou, L. Zhao, P. Fan, Validated LC/MS/MS assay for curcumin and tetrahydrocurcumin in rat plasma and application to pharmacokinetic study of phospholipid complex of curcumin, J. Pharm. Biomed. Anal. 40 (2006) $720-727$.

[130] S.K. Vareed, M. Kakarala, M.T. Ruffin, J.A. Crowell, D.P. Normolle, Z. Djuric, D.E. Brenner, Pharmacokinetics of curcumin conjugate metabolites in healthy human subjects, Cancer Epidemiol. Biomarkers Prev. 17 (2008) $1411-1417$

[131] J. Su, K. Sripanidkulchai, Y. Hu, R. Chaiittianan, B. Sripanidkulchai, Increased in situ intestinal absorption of phytoestrogenic diarylheptanoids from Curcuma comosa in nanoemulsions, AAPS Pharm. Sci. Tech. 14 (2013) 1055-1062.

[132] J. Su, K. Sripanidkulchai, A. Suksamrarn, Y. Hu, P. Piyachuturawat, B. Sripanidkulchai, Pharmacokinetics and organ distribution of diarylheptanoid phytoestrogens from Curcuma comosa in rats, J. Nat. Med. 66 (2012) 468-475.

[133] J.S. Han, S. Lee, H.Y. Kim, C.H. Lee, MS-based metabolite profiling of aboveground and root components of Zingiber mioga and Officinale, Molecules 20 (2015) 16170-16185.

[134] X. Ma, D.R. Gang, Metabolic profiling of in vitro micropropagated and conventionally greenhouse grown ginger (Zingiber officinale), Phytochemistry 67 (2006) 2239-2255.

[135] H. Jiang, B.N. Timmermann, D.R. Gang, Characterization and identification of diarylheptanoids in ginger (Zingiber officinale Rosc.) using high-performance liquid chromatography/electrospray ionization mass spectrometry, Rapid Commun. Mass Spectrom. 21 (2007) 509-518.
[136] X.-L. Cheng, Q. Liu, Y.-B. Peng, L.-W. Qi, P. Li, Steamed ginger (Zingiber officinale): Changed chemical profile and increased anticancer potential, Food Chem. 129 (2011) 1785-1792.

[137] J.-O. Zhang, Y. Wang, H.-L. Li, Q. Wen, H. Yin, N.-K. Zeng, W.-Y. Lai, N. Wei, S.-Q. Cheng, S.-L. Kang, F. Chen, Y.-B. Li, Simultaneous quantification of seventeen bioactive components in rhizome and aerial parts of Alpinia officinarum Hance using LC-MS/MS, Anal. Methods 7 (2015) 4919-4926.

[138] F. Chen, H.-L. Li, Y.-F. Tan, W.-W. Guan, J.-Q. Zhang, Y.-H. Li, Y.-S. Zhao, Z.-M. Qin, Different accumulation profiles of multiple components between pericarp and seed of Alpinia oxyphylla capsular fruit as determined by UFLC-MS/MS, Molecules 19 (2014) 4510-4523.

[139] A. Saxena, D. Yadav, S. Mohanty, H.S. Cheema, M.M. Gupta, M.P. Darokar, D.U. Bawankule, Diarylheptanoids rich fraction of Alnus nepalensis attenuates malaria pathogenesis: in-vitro and in-vivo study, Phytother. Res. 30 (2016) 940-948.

[140] T.D. Ackrill, H.A. Sparkes, C.L. Willis, Synthesis of diarylheptanoid scaffolds inspired by calyxins I and J, Org. Lett. 17 (2015) 3884-3887.

[141] L.N. Lundgren, H. Pan, O. Theander, H. Eriksson, U. Johansson, M. Svenningsson, Development of a new chemical method for distinguishing between Betula pendula and Betula pubescens in Sweden, Can. J. For. Res. 25 (1995) 1097-1102.

[142] J. Liu, M. Meng, C. Li, X. Huang, D. Dia, Simultaneous determination of three diarylheptanoids and an $\alpha$-tetralone derivative in the green walnut husks (Juglans regia L.) by high-performance liquid chromatography with photodiode array detector. J. Chromatogr. A 1190 (2008) 80-85.

[143] T. Esposito, F. Sansone, S. Franceschelli, P. Del Gaudio, P. Picerno, R.P. Aquino, T. Mencherini, Hazelnut (Corylus avellana L.) shells extract: phenolic composition, antioxidant effect and cytotoxic activity on human cancer cell lines, Int. J. Mol. Sci. 18 (2017) 392, http://dx.doi.org/10.3390/ijms18020392.

[144] E. Riethmüller, Á. Alberti, G. Tóth, S. Béni, F. Ortolano, Á. Kéry, Characterisation of diarylheptanoid- and flavonoid-type phenolics in Corylus avellana L. leaves and bark by HPLC/DAD-ESI/MS, Phytochem. Anal. 24 (2013) 493-503.

[145] E. Riethmüller, G. Tóth, Á. Alberti, K. Végh, I. Burlini, Á. Könczöl, G.T. Balogh, Á. Kéry, First characterisation of flavonoid- and diarylheptanoid-type antioxidant phenolics in Corylus maxima by HPLC-DAD-ESI-MS, J. Pharm. Biomed. Anal. 107 (2015) 159-167.

[146] M. Masullo, A. Mari, A. Cerulli, A. Bottone, B. Kontek, B. Olas, C. Pizza, S. Piacente, Quali-quantitative analysis of the phenolic fraction of the flowers of Corylus avellana, source of the Italian PGI product Nocciola di Giffoni: isolation of antioxidant diarylheptanoids, Phytochemistry 130 (2016) 273-281.

[147] A. Khurana, C.-T. Ho, High performance liquid chromatographic analysis of curcuminoids and their photo-oxidative decomposition compounds in Curcuma longa 1, J. Liq. Chromatogr. 11 (1988) 2295-2304.

[148] G.K. Jayaprakasha, L.J. Mohan Rao, K.K. Sakariah, Improved HPLC method for the determination of curcumin demethoxycurcumin, and bisdemethoxycurcumin, J. Agric. Food Chem. 50 (2002) 3668-3672

[149] H.H. Tønnesen, J. Karlsen, High-performance liquid chromatography of curcumin and related compounds, J.Chromatogr 259 (1983) 367-371.

[150] R.L. Rouseff, High performance liquid chromatographic separation and spectral characterization of the pigments in turmeric and annatto, J. Food Sci. 53 (1988) 1823-1826

[151] B.-K. Jadhav, K.-R. Mahadik, A.-R. Paradkar, Development and validation of improved reversed phase-HPLC method for simultaneous determination of curcumin, demethoxycurcumin and bis-demethoxycurcumin, Chromatographia 65 (2007) 483-488.

[152] R. Bos, T. Windono, H.J. Woerdenbag, Y.L. Boersma, A. Koulman, O. Kayser, HPLC-photodiode array detection analysis of curcuminoids in Curcume species indigenous to Indonesia, Phytochem. Anal. 18 (2007) 118-122.

[153] D.D. Heath, M.A. Pruitt, D.E. Brenner, C.L. Rock, Curcumin in plasma and urine: quantitation by high-performance liquid chromatography, J. Chromatogr. B Analyt. Technol. Biomed. Life Sci. 783 (2003) 287-295.

[154] R. Barbara, D. Belletti, F. Pederzoli, M. Masoni, J. Keller, A. Ballestrazzi, M.A. Vandelli, G. Tosi, A.M. Grabrucker, Novel Curcumin loaded nanoparticles engineered for blood-brain barrier crossing and able to disrupt abeta aggregates, Internat. J. Pharm. 526 (2017) 413-424.

[155] H.H. Tønnesen, M. Másson, T. Loftsson, Studies of curcumin and curcuminoids. XXVII. Cyclodextrin complexation: solubility, chemical and photochemical stability, Int. J. Pharm. 244 (2002) 127-135.

[156] M.-H. Pan, T.-M. Huang, J.-K. Lin, Biotransformation of curcumin through reduction and glucuronidation in mice, Drug Metab. Dispos. 27 (1999) 486-494.

[157] J.K. Kim, C. Jo, H.J. Hwang, H.J. Park, Y.J. Kim, M.W. Byun, Color improvement by irradiation of Curcuma aromatica extract for industrial application, Radiat. Phys. Chem. 75 (2006) 449-452.

[158] Q. Zhang, C. Cui, C.-Q. Chen, X.-L. Hu, Y.-H. Liu, Y.-H. Fan, W.-H. Meng, Q.-C. Zhao, Anti-proliferative and pro-apoptotic activities of Alpinia oxyphylla on HepG2 cells through ROS-mediated signaling pathway, J. Ethnopharmacol. 169 (2015) 99-108.

[159] J. Liimatainen, M. Karonen, J. Sinkkonen, M. Helander, J.-P. Salminen, Phenolic compounds of the inner bark of Betula pendula: seasonal and genetic variation and induction by wounding, J. Chem. Ecol. 38 (2012) 1410-1418.

[160] G. Telysheva, T. Dizhbite, O. Bikovens, J. Ponomarenko, S. Janceva, J. Krasilnikova, Structure and antioxidant activity of diarylheptanoids 
extracted from bark of grey alder (Alnus incana) and potential of biorefinery-based bark processing of European trees, Holzforschung 65 (2011) 623-629.

[161] F.S. Santamour, Jr, L.N. Lundgren, Distribution and inheritance of platyphylloside in Betula, Biochem. Syst. Ecol. 24 (1996) 145-156.

[162] N.R. Guz, P. Lorenz, J.-P. Métraux, Oregonin from the bark of European Alnus species, Biochem. Syst. Ecol. 30 (2002) 471-474

[163] K.Y. Moon, B.K. Ahn, S.G. Lee, S.H. Lee, D.W. Yeom, Y.W. Choi, Enhanced aqueous stability of hirsutenone with antioxidant, J. Pharm. Investig. 41 (2011) 331-336.

[164] B.K. Ahn, S.G. Lee, S.R. Kim, D.H. Lee, M.H. Oh, M.W. Lee, Y.W. Choi, Inclusion compound formulation of hirsutenone with beta-cyclodextrin, J. Pharm. Investig. 43 (2013) 453-459.

[165] E. Riethmüller, Á. Könczöl, D. Szakál, K. Végh, G.T. Balogh, Á. Kéry, HPLC-DPPH screening method for evaluation of antioxidant compounds in Corylus species, Nat. Prod. Commun. 11 (2016) 641-644.

[166] U. Pedersen, P.B. Rasmussen, S.-O. Lawesson, Synthesis of naturally occurring curcuminoids and related compounds, Liebigs Ann. Chem. (1985) 1557-1569

[167] A. Navas Díaz, M.C. Ramos Peinado, Fluorometric determination of curcumin in yogurt and mustard, J. Agric. Food Chem. 40 (1992) 56-59.

[168] Z. Liu, S. Sang, T.G. Hartman, C.-T. Ho, R.T. Rosen, Determination of diarylheptanoids from Alpinia officinarum (Lesser galangal) by HPLC with photodiode array and electrochemical detection, Phytochem. Anal. 16 (2005) 252-256.

[169] X. Ma, D.R. Gang, Metabolic profiling of turmeric (Curcuma longa L.) plants derived from in vitro micropropagation and conventional greenhouse cultivation, J. Agric. Food Chem. 54 (2006) 9573-9583.

[170] P.B. Luis, O.N. Gordon, F. Nakashima, A.I. Joseph, T. Shibata, K. Uchida, C. Schneider, Oxidative metabolism of curcumin-glucuronide by peroxidases and isolated human leukocytes, Biochem. Pharmacol. 132 (2017) 143-149.

[171] Y. Zeng, F. Qiu, Y. Liu, G. Qu, X. Yao, Isolation and identification of phase 1 metabolites of demethoxycurcumin in rats, Drug Metab. Dispos. 35 (2007) 1564-1573.

[172] Z. Xie, X. Ma, D.R. Gang, Modules of co-regulated metabolites in turmeric (Curcuma longa) rhizome suggest the existence of biosynthetic modules in plant specialized metabolism, J. Exp. Bot. 60 (2009) 87-97.

[173] R. Hiserodt, T.G. Hartman, C.-T. Ho, R.T. Rosen, Characterization of powdered turmeric by liquid chromatography-mass spectrometry and gas chromatography-mass spectrometry, J. Chromatogr. A. 740 (1996) 51-63.

[174] S. Wang, Y. Zhao, J. Zhang, X. Huang, Y. Wang, X. Xu, B. Zheng, X. Zhou, H. Tian, L. Liu, Q. Mei, Antidiarrheal effect of Alpinia oxyphylla Miq.

(Zingiberaceae) in experimental mice and its possible mechanism of action, J.Ethnopharmacol 168 (2015) 182-190.

[175] S.-L. Zeng, X.-G. Liu, C.-J.-S. Lai, E.-H. Liu, P. Li, Diagnostic ion filtering strategy for chemical characterization of Guge Fengtong Tablet with high-performance liquid chromatography coupled with electrospray ionization quadrupole time-of-flight tandem mass spectrometry, Chin. J. Nat. Med. 13 (2015) 390-400.

[176] S.L. Jackrel, T.C. Morton, J.T. Wootton, Intraspecific leaf chemistry drives locally accelerated ecosystem function in aquatic and terrestrial communities, Ecology 97 (2016) 2125-2135.

[177] H. Jiang, B.N. Timmermann, D.R. Gang, Use of liquid chromatography-electrospray ionization tandem mass spectrometry to identify diarylheptanoids in turmeric (Curcuma longa L.) rhizome, J. Chromatogr. A 1111 (2006) 21-31.
[178] J. Liimatainen, M. Karonen, J. Sinkkonen, M. Helander, J.-P. Salminen, Characterization of phenolic compounds from inner bark of Betula pendula, Holzforschung 66 (2012) 171-181.

[179] V.L. Muilenburg, P.L. Phelan, P. Bonello, D.A. Herms, Inter- and intra-specific variation in stem phloem phenolics of paper birch (Betula papyrifera) and european white birch (Betula pendula), J. Chem. Ecol. 37 (2011) 1193-1202.

[180] E. Riethmüller, G. Tóth, Á. Alberti, M. Sonati, Á. Kéry, Antioxidant activity and phenolic composition of Corylus colurna, Nat. Prod. Commun. 9 (2014) 679-682.

[181] S. Burapan, M. Kim, J. Han, Curcuminoid demethylation as an alternative metabolism by human intestinal microbiota, J. Agric. Food Chem. 65 (2017) 3305-3310.

[182] F. Chen, H.-L. Li, Y.-F. Tan, Y.-H. Li, W.-Y. Lai, W.-W. Guan, J.-Q. Zhang, Y.-S. Zhao, Z.-M. Qin, Identification of known chemicals and their metabolites from Alpinia oxyphylla fruit extract in rat plasma using liquid chromatography/tandem mass spectrometry (LC-MS/MS) with selected reaction monitoring, J. Pharm. Biomed. Anal. 97 (2014) 166-177.

[183] O.N. Gordon, P.B. Luis, R.E. Ashley, N. Osheroff, C. Schneider, Oxidative transformation of demethoxy- and bisdemethoxycurcumin: products, mechanism of formation, and poisoning of human topoisomerase II $\alpha$, Chem. Res. Toxicol. 28 (2015) 989-996.

[184] S.D. Jolad, R.C. Lantz, A.M. Solyom, G.J. Chen, R.B. Bates, B.N. Timmermann, Fresh organically grown ginger (Zingiber officinale): composition and effects on LPS-induced PGE2 production, Phytochemistry 65 (2004) 1937-1954.

[185] S.D. Jolad, R.C. Lantz, G.J. Chen, R.B. Bates, B.N. Timmermann, Commercially processed dry ginger (Zingiber officinale): Composition and effects on LPS-stimulated PGE2 production, Phytochemistry 66 (2005) 1614-1635.

[186] D.J. Harvey, Gas chromatographic and mass spectrometric studies of ginger constituents. identification of gingerdiones and new hexahydrocurcumin analogues, J. Chromatogr. 212 (1981) 75-84.

[187] E. Hiltunen, T.T. Pakkanen, L. Alvila, Phenolic compounds in silver birch (Betula pendula Roth) wood, Holzforschung 60 (2006) 519-527.

[188] M. Lechtenberg, B. Quandt, A. Nahrstedt, Quantitative determination of curcuminoids in Curcuma rhizomes and rapid differentiation of Curcuma domestica val. and Curcuma xanthorrhiza roxb. by capillary electrophoresis, Phytochem. Anal. 15 (2004) 152-158.

[189] K. Yuan, Q. Weng, H. Zhang, J. Xiong, G. Xu, Application of capillary zone electrophoresis in the separation and determination of the curcuminoids in urine, J. Pharm. Biomed. Anal. 38 (2005) 133-138.

[190] C. Li, J.-X. Liu, L. Zhao, D.-L. Di, M. Meng, S.-X. Jiang, Capillary zone electrophoresis for separation and analysis of four diarylheptanoids and an $\alpha$-tetralone derivative in the green walnut husks (Juglans regia L.), J. Pharm. Biomed. Anal. 48 (2008) 749-753.

[191] T. Watanabe, T.K. Mazumder, A. Yamamoto, S. Nagai, S. Terabe, Separation and determination of curcuminoids in turmeric samples by micellar electrokinetic chromatography with a high molecular mass surfactant, J. Jpn. Soc. Food Sci. 47 (2000) 780-786.

[192] T. Nhujak, W. Saisuwan, M. Srisa-art, A. Petsom, Microemulsion electrokinetic chromatography for separation and analysis of curcuminoids in turmeric samples, J. Sep. Sci. 29 (2006) 666-676. 